\title{
Preliminary Bounds on the Water Composition and Secondary Mineral Development That May Influence the Near-Field Environment
}

\author{
M. Whitbeck \\ W. Glassley
}

February 1998

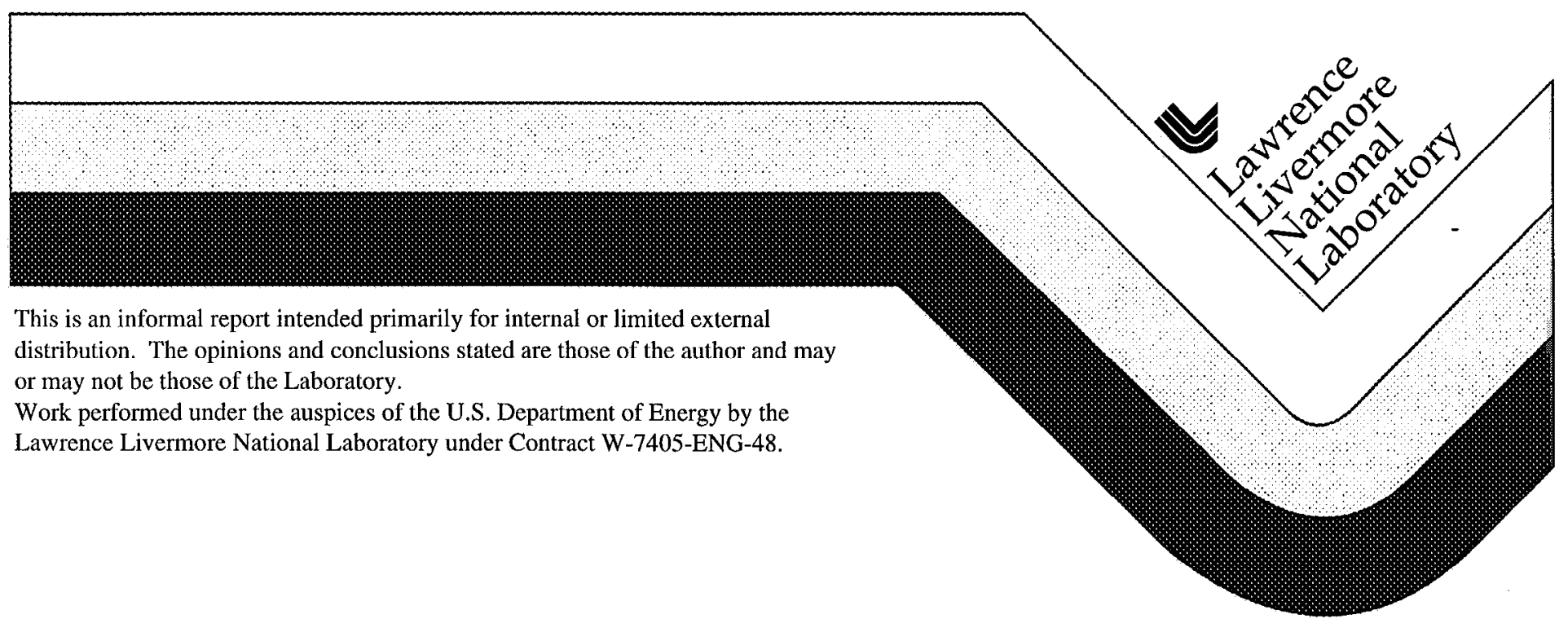




\section{DISCLAIMER}

This document was prepared as an account of work sponsored by an agency of the United States Government. Neither the United States Government nor the University of California nor any of their employees, makes any warranty, express or implied, or assumes any legal liability or responsibility for the accuracy, completeness, or usefulness of any information, apparatus, product, or process disclosed or represents that its use would not infringe privately owned rights. Reference herein to any specific commercial product, process, or service by trade name, trademark, manufacturer, or otherwise, does not necessarily constitute or imply its endorsement, recommendation, or favoring by the United States Government or the University of California. The views and opinions of authors expressed herein do not necessarily state or reflect those of the United States Government or the University of California, and shall not be used for advertising or product endorsement purposes.

This report has been reproduced directly from the best available copy.

Available to DOE and DOE contractors from the Office of Scientific and Technical Information P.O. Box 62, Oak Ridge, TN 37831

Prices available from (423) 576-8401

Available to the public from the National Technical Information Service

U.S. Department of Commerce

5285 Port Royal Rd.,

Springfield, VA 22161 


\title{
Preliminary Bounds on the Water Composition and Secondary Mineral Development That May Influence the Near- Field Environment
}

\author{
Michael Whitbeck and William Glassley \\ Earth Sciences Division, Lawrence Livermore National Laboratory \\ Livermore, California 94550
}

\begin{abstract}
The evolution of the water chemistry and secondary mineral development in the vicinity of the near-field of a potential Yucca Mountain high level nuclear waste repository will be controlled by temperature, and interaction of water with the rock over time. This report describes initial bounds on water composition and secondary mineral development, as a function of time, temperature, and rock type (devitrified, welded tuff and vitrophyre). The code EQ3/6 was used in the calculations, with explicit use of transition state theory models for mineral dissolution rates for the framework minerals of the tuff. Simulations were run for time durations sufficient to achieve steady state. conditions. Uncertainty in the calculations, due to uncertainty in the measured dissolution rates, was considered by comparing results in simulations in which rates were varied within the range of known uncertainties for dissolution rate constants. The results demonstrate that the steady state mineralogy and water compositions are relatively insensitive to the rock unit modeled, which is consistent with the fact that the compositions of the rock units in the vicinity of the potential repository are similar, and will tend toward similar thermodynamic free energy minima, for similar rock-water ratios. Significant differences are observed, however, for large differences in rock:water ratios. The rates at which this end point condition are approached are a function of the rate parameters used, and can vary by onders of magnitude.
\end{abstract}




\section{Introduction}

It has long been evident that emplacement of high level nuclear waste at the potential repository at Yucca Mountain would result in a complex thermal evolution of the repository block. Temperatures significantly above boiling may develop under some waste package emplacement strategies, if one considers current repository operating scenarios (Nitao, 1988; Buscheck and Nitao, 1992, 1993). Although the proposed repository site is within the unsaturated zone, ambient saturation of matrix pore volumes is as high as $75 \%$. Heatdriven evaporation, boiling, and condensation processes will lead to movement of water vapor away from the repository, resulting in increased saturation of some rocks within some parts of the repository block. In some cases, the saturation may approach $100 \%$ under some operation scenarios after waste is emplaced. During cool down, or as a result of rapid fracture flow, it is possible that liquid water may return to or enter the near-field environment (NFE), which could result in a net increase in total water present in the NFE. Most of the minerals currently present in the rock making up the potential repository horizon are not in thermodynamic equilibrium with water at elevated temperatures. As a result, water will interact with existing minerals, causing new minerals to form, existing minerals to change their compositions or dissolve, and modifying the water chemistry in the process. In order to bound these effects a program to model the reaction process has been undertaken. This letter report summarizes the preliminary results of the initial steps in this activity.

\section{Approach}

Rock units considered in the simulations were the Tsw2 and Tsw 3 units of the Topopah Spring tuff. The Tsw 2 was selected because it is the rock that makes up the potential repository horizon. The Tsw3 (basal vitrophyre unit) was selected because the Tsw2 is a heterogeneous unit, containing many blocks and fragments of minerals and rocks, including blocks and fragments of pumiceous and/or glassy material that will alter in a manner similar to that expected for the Tsw3. The mineral abundances for the Tsw 2 unit were taken from Delany (1985). The dissolution rates of the mineral phases, and the surfaces areas, were also taken from Delany (1985). The glass composition was taken to be that of Sample 2A from Table II of Broxton et al (1989). The EQ3/6 code (Wolery, 1992 a,b; Wolery et al., 1990; Wolery and Daveler, 1992) was used for the simulations (version 
7.2a). The database used was COM, version 22a. All calculations were done using the "Bdot" activity coefficient model (see Wolery, 1992b for a description of this model).

Water composition reacting with the rock materials was assumed to be that of $\mathrm{J}-13$. water. The composition used was the average composition reported in Harrar et al (1990).

In the conceptual model used for these simulations, it was assumed that sufficient water was available to allow complete reaction of the rock material. It was also assumed that reaction would take place in a system open to the atmosphere. Hence, the coexisting gas phase had a constant $\mathrm{H}_{2} \mathrm{O}$ and $\mathrm{CO}_{2}$ partial pressure equivalent to that of present day atmosphere ( 0.2 and 0.003 bars, respectively). Reaction progress was constrained to be sufficiently large to allow steady state to be achieved for the tuffs. In the case of the waterglass simulations, the extent of reaction progress was determined by the amount of glass present and the dissolution rate.

Simulations were conducted for both rock types at $40,50,60,75$ and $90^{\circ} \mathrm{C}$. This temperature interval was selected because it covers the range between ambient conditions and boiling. Reaction of rock and water at higher temperatures will be conducted at a later time when the EQ3/6 code has been modified to simulate reactions off the liquid-vapor saturation curve of water.

Quartz, talc, and tridymite were suppressed from precipitation in all of the runs. This was done because these phases, although less soluble than other silica polymorphs or hydrous Mg-silicates, do not readily precipitate due to kinetic barriers. It may be, however, that after sufficient time has passed in natural systems, these phases would appear, as the kinetic barriers are overcome. In that case, inclusion of these phases would be appropriate at some point in the reaction progress. When sufficient information is available to reasonably simulate this process, the type of simulations reported here will be redone.

To evaluate the effect of uncertainty in the dissolution rate, two methods were used. One method evaluated the propagation of error in a generalized reaction sequence:

$$
A \Leftrightarrow B \Leftrightarrow C
$$

This simple system has an exact analytical solution yet is sufficiently general to represent many of the subsets of more complex geochemical systems when they are not strongly coupled with other parts of the system. This approach provides a view of the conditions under which uncertainty may be an important consideration in understanding reaction progress. The second method utilized is simulation of the reactions of water with the volcanic rocks, using different rate constants. This method allows representation of the specific effects on the simulations described in this study.

The effect of different rates of glass dissolution was examined by using a slow relative rate constant $(8.66 \mathrm{E}-14)$ and a very fast relative rate constant $(4.0 \mathrm{E}-4)$ in different 
suites of runs. This wide range of rates was selected because the effective surface area that the fluid will interact with is unknown. Overall reaction rate is a function of surface area, and can vary over many orders of magnitude depending, for example, whether water flows only along a preferred flow pathway in a fracture, or permeates a rock with small glass shards and which, consequently, possess a large effective surface area. Hence, such a wide range of rate constants was selected as a means of bounding these effects. In order to evaluate these effects, the runs with a slow reaction rate constant had a total mass of .1735 grams (.08029 moles) of glass per $\mathrm{kg}$ of water and the runs with the fast reaction rate constants had 17.29 grams ( 8.0 moles) of glass (where the glass molecular weight was arbitrarily chosen to be 2.21454 grams).

Previous efforts to evaluate error propagation in generalized systems (e.g., Brisqueu \& de la Boisse (1990), and Thompson and Stewart, 1991) have utilized Monte Carlo techniques. For our purposes, such generality is not of interest. Rather, we are interested in establishing uncertainties for particular calculations. Given this criteria, a simple differencing scheme is employed to determine the sensitivity of the model results to uncertainty in kinetics parameters.

For the first method, the relative error propagated into the final product of a model system as a function of relative error in the two forward reaction rates $\left(k_{1}\right.$ and $\left.k_{2}\right)$ is $(\alpha$ and $\beta$ are parameters in the analytical solution of $A \Leftrightarrow B \Leftrightarrow C$ model system, $A(t), B(t)$, and $C(t)$ are the amounts of each species in the model system, as a function of time, $A_{0}$ is the amount of $A$ at time $t=0$, and $t$ is time):

$$
\begin{aligned}
B(t) & =k_{1} A_{0}\left[\frac{k_{2}}{\alpha \beta}+\frac{k_{-2}-\alpha}{\alpha(\alpha-\beta)} e^{-\alpha t}-\frac{k_{-2}-\beta}{\beta(\alpha-\beta)} e^{-\alpha t}\right] \\
C(t) & =k_{1} k_{2} A_{0}\left[\frac{1}{\alpha \beta}+\frac{1}{\alpha(\alpha-\beta)} e^{-\alpha t}-\frac{1}{\beta(\alpha-\beta)} e^{-\alpha t}\right]
\end{aligned}
$$

where

$$
\begin{aligned}
\alpha \beta & =k_{1} k_{2}+k_{1} k_{-2}+k_{-1} k_{2} \\
\alpha+\beta & =k_{1}+k_{-1}+k_{2}+k_{-2}
\end{aligned}
$$


The relative error propagated to $C(t)$ is given by

$$
\begin{aligned}
&(\delta C)^{2}=\left(\frac{\partial C}{\partial k_{1}}\right)^{2} \delta k_{1}^{2}+\left(\frac{\partial C}{\partial k_{-1}}\right)^{2} \delta k_{-1}^{2}+\left(\frac{\partial C}{\partial k_{2}}\right)^{2} \delta k_{2}^{2}+\left(\frac{\partial C}{\partial k_{-2}}\right)^{2} \delta k_{-2}^{2} \\
&\left(\partial C / \partial k_{1}\right)=C / k_{1}+W\left(k_{1}\right) \\
&\left(\partial C / \partial k_{-1}\right)=W\left(k_{-1}\right) \\
&\left(\partial C / \partial k_{2}\right)=C / k_{2}+W\left(k_{2}\right) \\
&\left(\partial C / \partial k_{-2}\right)=W\left(k_{-2}\right)
\end{aligned}
$$

and

$$
\begin{aligned}
& W\left(k_{i}\right)=-\frac{1}{\alpha^{2} \beta} \frac{\partial \alpha}{\partial k_{i}}-\frac{1}{\alpha \beta^{2}} \frac{\partial \beta}{\partial k_{i}} \\
&-e^{-\alpha t} \frac{1}{\alpha^{2}(\alpha-\beta)^{2}}\left(2 \alpha \frac{\partial \alpha}{\partial k_{i}}-\beta \frac{\partial \alpha}{\partial k_{i}}-\alpha \frac{\partial \beta}{\partial k_{i}}\right) \\
&-\frac{t}{\alpha(\alpha-\beta)} \frac{\partial \alpha}{\partial k_{i}} e^{-\alpha t}+\frac{t}{\beta(\alpha-\beta)} \frac{\partial \beta}{\partial k_{i}} c^{-\beta t} \\
&+e^{-\rho t} \frac{1}{\beta^{2}(\alpha-\beta)^{2}}\left(\alpha \frac{\partial \beta}{\partial k_{i}}+\beta \frac{\partial \alpha}{\partial k_{i}}-2 \beta \frac{\partial \beta}{\partial k_{i}}\right) \\
& \frac{\partial \alpha}{\partial k_{i}}= 1-\frac{\partial \beta}{\partial k_{i}} \\
& \frac{\partial \beta}{\partial k_{1}}= \frac{1}{2} \pm \frac{1}{4}\left[\left(\sum k_{i}\right)^{2}-4 \eta\right]^{-1 / 2}\left[2 \sum k_{i}-4 k_{2}-4 k_{-2}\right] \\
& \frac{\partial \beta}{\partial k_{-1}}=\frac{1}{2} \pm \frac{1}{4}\left[\left(\sum k_{i}\right)^{2}-4 \eta\right]^{-1 / 2}\left[2 \sum k_{i}-4 k_{2}\right] \\
& \frac{\partial \beta}{\partial k_{2}}=\frac{1}{2} \pm \frac{1}{4}\left[\left(\sum k_{i}\right)^{2}-4 \eta\right]^{-1 / 2}\left[2 \sum k_{i}-4 k_{1}-4 k_{-1}\right] \\
& \frac{\partial \beta}{\partial k_{-2}}=\frac{1}{2} \pm \frac{1}{4}\left[\left(\sum k_{i}\right)^{2}-4 \eta\right]^{-1 / 2}\left[2 \sum k_{i}-4 k_{1}\right] \\
& \eta= k_{1} k_{2}+k_{1} k_{-2}+k_{-1} k_{2} \\
& \delta k_{-1} \equiv 0 \\
& \delta k_{-2} \equiv 0
\end{aligned}
$$

Rev. 0 
At long times the exponential terms approach zero leaving the error propagation terms proportionate to the uncertainties $\delta \mathrm{k}_{\mathrm{i}}$ scaled by a function of the rate constants, $\mathrm{k}_{\mathrm{i}}$. The largest errors will occur at some point, $t$, prior to the vanishing of the exponential terms in $\mathrm{W}\left(\mathrm{ki}_{\mathrm{i}}\right)$. After that the scaling function determines whether or not a magnification of crrors persist in the final values for chemical constituents in the calculation. Computations to determine the magnitude of the propagated error were done for several sets of starting conditions.

To further address the significance of error propagation, a simple differencing scheme was applied to a simulation of sanidine dissolution. Error propagation occurs as infinitesimally small changes in composition with correspondingly small changes in the parameters (equation 5). This finite difference equation can be solved numerically using geochemical modeling codes (e.g. EQ 6). However, evaluating the error in a calculation is also dependent upon the computational performance of the modeling code; for simulations in which there is a small difference in the input data from one simulation to another, accumulation of round-off error and truncation errors may overshadow the propagated error related to uncertainty in the input parameters.

To illustrate these effects, we consider dissolution of sanidine, which has a measured dissolution rate constant of $5 \times 10^{-15}$ moles/cm ${ }^{2}$-sec (Holdren and Speyer, 1985). In a simple system the effect of increasing the rate constant by a small amount might be expected to simply increase the rate of reaction while decreasing the rate of reaction correspondingly should result in a retardation of the simulated results. Intuitively this is also the expected in this case since, in theory at least, we can always pick an increase (decrease) in the sanidine dissolution rate constant sufficiently small as to be inconsequential. The value in doing this is that it allows a numerical approximation to the partial derivative with respect to that rate constant for any of the computed results from the model. Thus the sensitivity of the model results to a given rate constant, in this case sanidine dissolution, may be examined.

\section{RESULTS}

The water compositions and secondary mineralogies obtained at steady state conditions, at a given temperature, for the tuffs are constrained by the fixed composition of the starting material, and the solubilities of the starting phases. For the vitric material, however, dissolution is treated as though it is congruent, hence, the amount of material dissolved (or, in other words, the extent of reaction progress) will determine the mineralogical products and water chemistry. In this case, therefore, a steady state 
composition will not be achieved, except under extreme conditions in which very high absolute amounts of glass are dissolved. The simulations conducted here were not taken to steady state for the glasses, because this would require dissolution of unrealistically large volumes of glass. Described below are the mineralogical and chemical results obtained for the different rock types.

\section{Secondary Mineralogy of the Tuffs (Figs, L L a -e)}

Throughout reaction progress saponite (a clay), carbonate and fluorapatite are present at low abundances at all temperatures. These phases are joined by clays (celadonite and smectite), authigenic feldspar (microcline), and zeolites (clinoptilolite at low temperature, stilbite at 50 and $75^{\circ} \mathrm{C}$, with mesolite present throughout the temperature range), relatively early in the reaction progress period, and they persist to steady state conditions. The actual time of appearance of specific phases depends upon temperature. At $40^{\circ} \mathrm{C}$, important secondary alumino-silicate phases do not appear until after approximately 100 days of reaction progress. At temperatures greater than $50^{\circ} \mathrm{C}$, important alumino-silicates appear within a few days. However, in all cases, steady state conditions. with relatively high abundances of secondary minerals are not approached until thousands of days have elapsed. In all cases, one of the last phases to appear is a silica polymorph (in this case, chalcedony), but it quickly becomes the most abundant secondary phase. At high temperatures $\left(90^{\circ} \mathrm{C}\right)$, garnet and tremolite appear in the secondary mineral assemblage. As discussed below, these phases probably would not be the stable phases that would form under these conditions, given evidence from metamorphic petrology in low temperature systems.

\section{Water Chemistry of the Tuffs (Figs, 2, a-g)}

The initial water composition reflects equilibration of $\mathrm{J}-13$ water at the temperature of the simulation. At all temperatures, this initial composition is moderately alkaline (pH of ca. 8.5 ), oxidizing (Eh between 580 and 680 millivolts), and has a low ionic strength (ca. 0.0028 molal). Concentrations of the dissolved elements are low (in decreasing order of abundance, they are $\mathrm{Na}$ [ca. $40 \mathrm{mg} / \mathrm{kg}$ ]; $\mathrm{Si}$ [ ca. $30 \mathrm{mg} / \mathrm{kg}$ ], $\mathrm{Cl}$ [ca. $10 \mathrm{mg} / \mathrm{kg}$ ], S [ca. 6.0 $\mathrm{mg} / \mathrm{kg}$ ], Ca [ca. $5 \mathrm{mg} / \mathrm{kg}$ ], F [ca. $2.0 \mathrm{mg} / \mathrm{kg}$ ], $\mathrm{Mg}$ [ca. $0.1 \mathrm{mg} / \mathrm{kg}$ ], Li [ca. $0.05 \mathrm{mg} / \mathrm{kg}$ ], Al [< 1.0E-4 mg/kg], and $P[2.0 \mathrm{E}-5 \mathrm{mg} / \mathrm{kg}])$.

Water composition remains relative constant, at a given temperature, until reaction progress reaches approximately 100 days, at which point the composition changes 
Figure 1: Secondary mineralogy as a function of time. a) $40^{\circ} \mathrm{C}$; b) $50^{\circ} \mathrm{C}$; c) $60^{\circ} \mathrm{C}$; d) $75^{\circ}$ $\mathrm{C}$; e) $90^{\circ} \mathrm{C}$. Mineralogy of the tuffs is shown as solid lines, mineralogy of the vitrophyre is shown as broken lines. These relationships for the vitrophyre are for the case in which the water:glass mass ratio is 5763. Rate constants and surface areas for the vitrophyre case were adjusted so that the time at which most of the secondary minerals developed was similar to that for the tuff. For the case in which the water:rock mass ratio was much lower (57.8), the same mineral phases developed for the vitrophyre during the early stages of reaction progress, but were eventually superseded by chalcedony and hematite. 


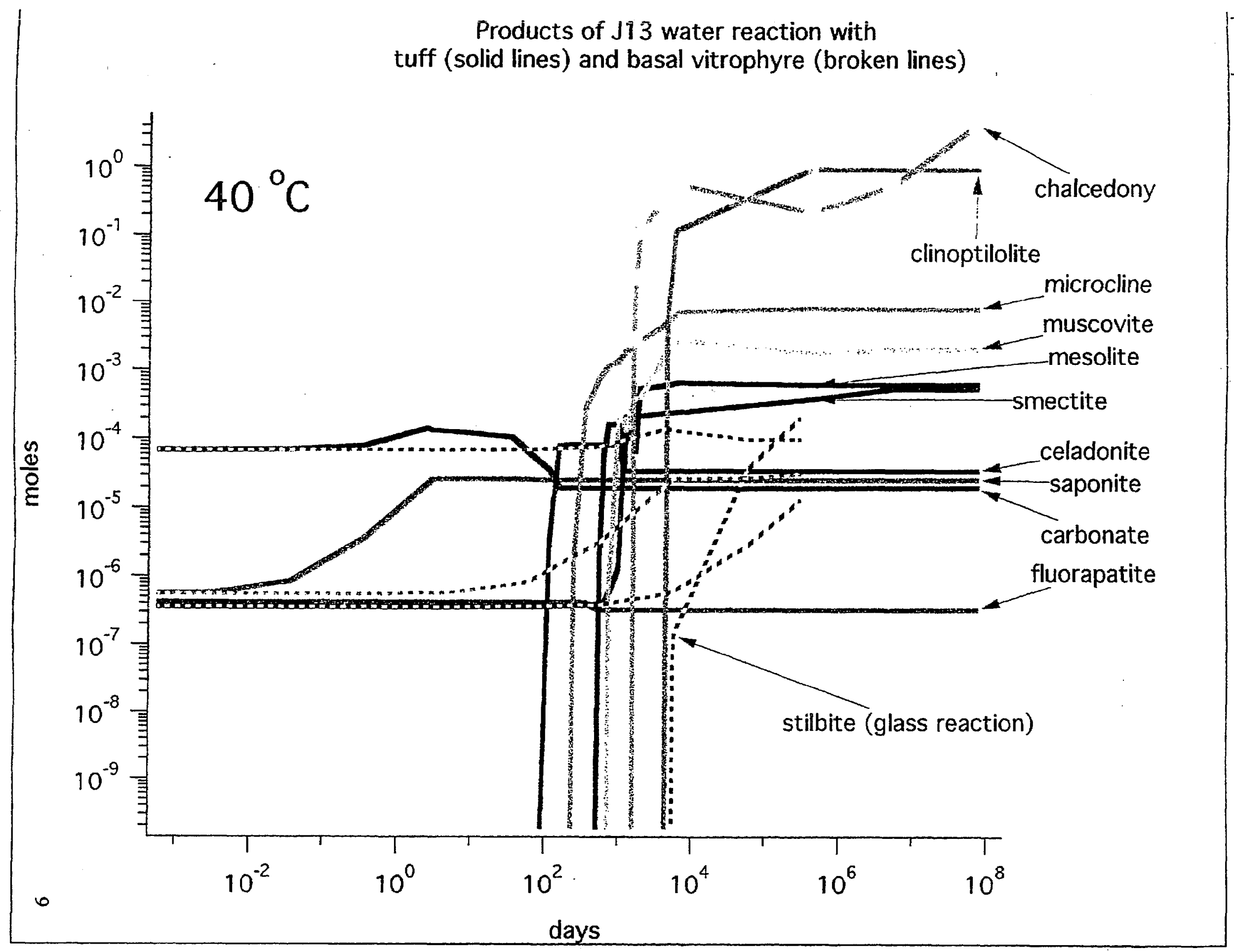


Products of $\mathrm{J13}$ water reaction with

tuff (solid lines) and basal vitrophyre (broken lines)

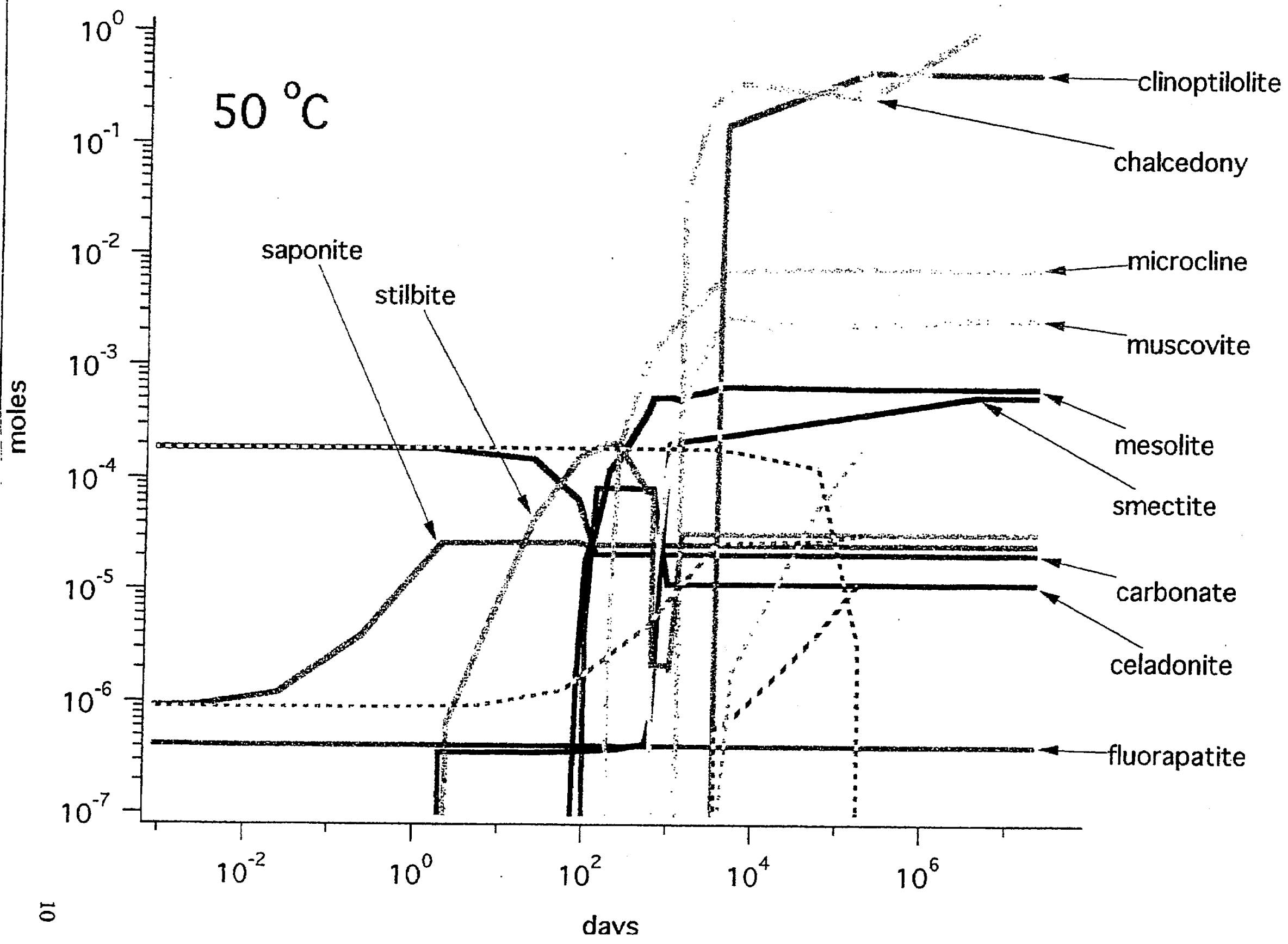




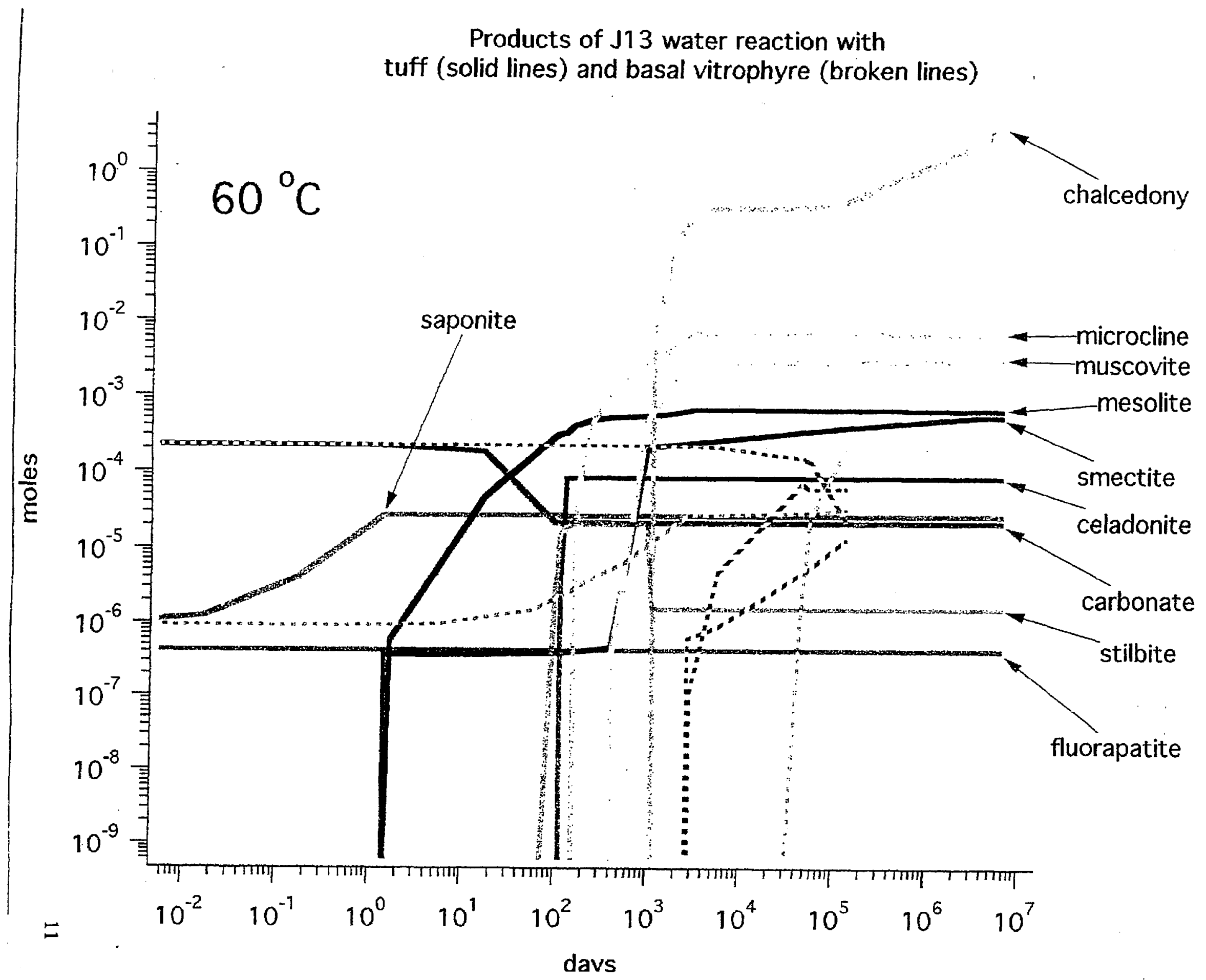




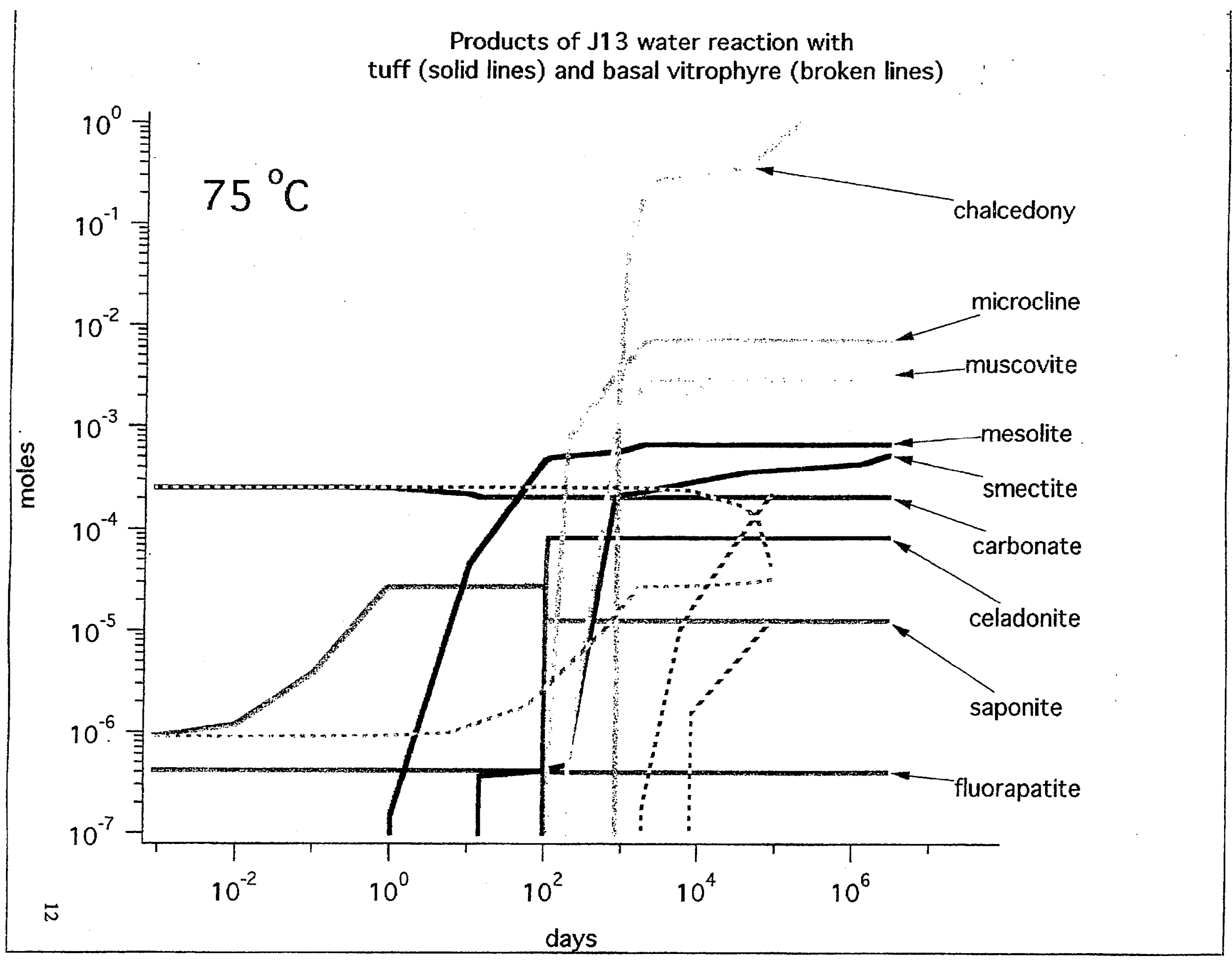




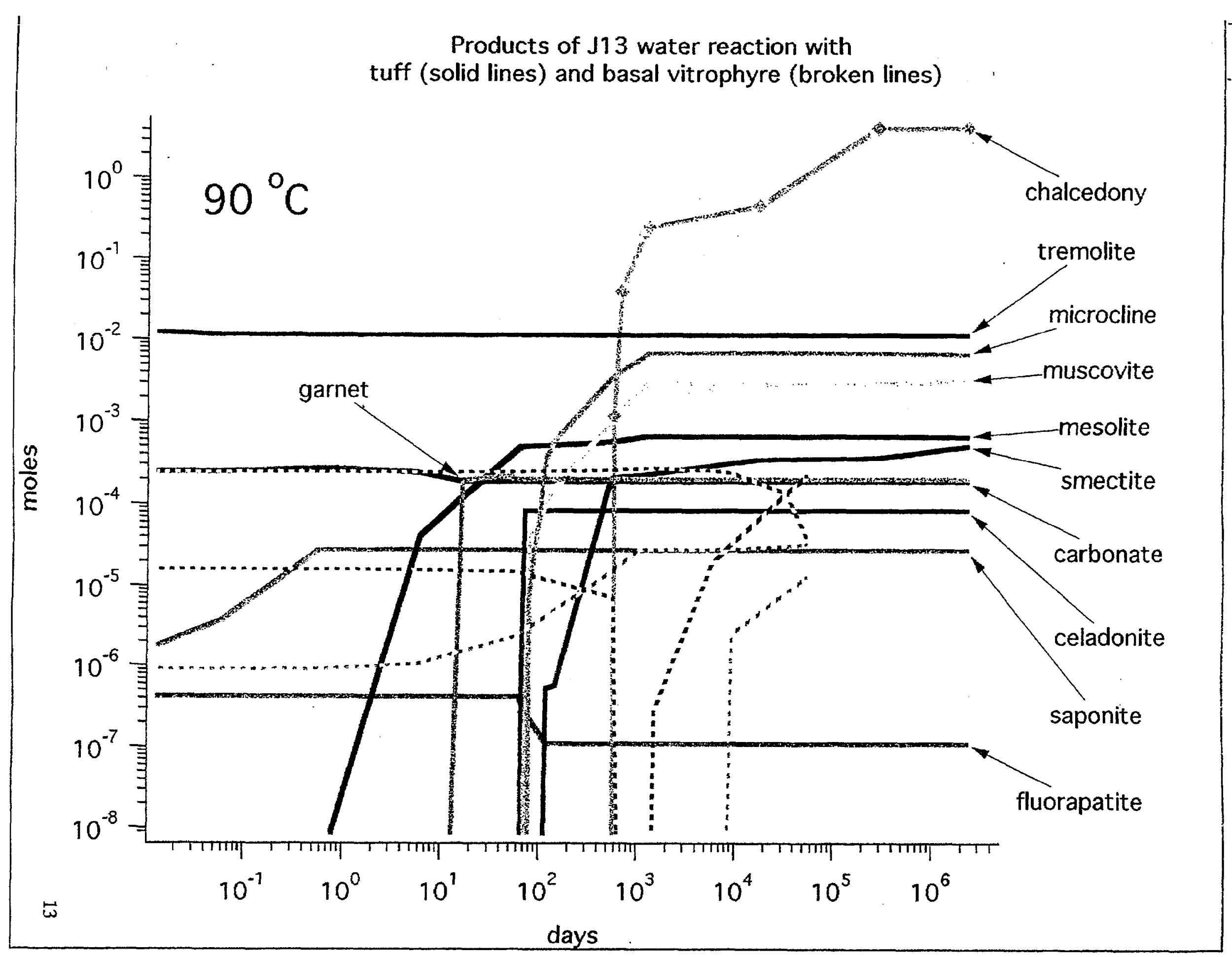


significantly due to formation of secondary mineral phases, and dissolution of significant quantities of the rock components. Calcium and magnesium are both largely removed from solution due to precipitation of carbonates and, to a lesser extent, a variety silicates.

The elements $\mathrm{Na}, \mathrm{Si}$, and $\mathrm{Al}$ increase significantly, even though they are incorporated in the secondary minerals, due to the fact that the amount added to solution by dissolution of the solids, is much greater than the amount removed by precipitation. Nevertheless, the final concentration reached for these elements is controlled by the solubilities of the major secondary phases. Silicon, for example, is buffered at chalcedony saturation, at steady state conditions. Other elements are controlled by a combination of secondary phases, since many of these phases are complex, multi-component solid solutions.

The redox state is effectively determined by the assumption that the solution is in equilibrium with atmospheric gases. Hence, total oxygen is assumed to be maintained at approximately $20 \%$ of the coexisting gas phase, at a log fugacity of -0.7 . This assumption ignores the temperature effect on fugacity, since the calculations are actually carried out on the liquid vapor saturation curve for $\mathrm{H}_{2} \mathrm{O}$. This assumption, however, has negligible effect on the results presented here, which are generated for the purpose of providing gross bounds to the water composition.

The variation in $\mathrm{pH}$ is strongly controlled by the fact that $\mathrm{CO}_{2}$ fugacity is fixed in the simulations. This parameter, in turn influences carbonic acid equilibria in such a way that $\mathrm{pH}$ remains slightly alkaline throughout reaction progress. However, the final steady state achieved differs by approximately one log unit between the $40^{\circ} \mathrm{C}$ and $90^{\circ} \mathrm{C}$ simulations.

The conservative elements $\mathrm{Cl}, \mathrm{F}, \mathrm{Li}$ and $\mathrm{P}$ show no significant variation during reaction progress because they are not incorporated into any secondary phases that form in significant quantities, other than apatite which maintains a constant abundance throughout the reaction progress. 
Milestone MOL205

Figure 2: Tuff-water system aqueous compositions, as a function of time and temperature. a) $\mathrm{pH}$; b) $\mathrm{Eh}$; c) $\mathrm{Si}$; d) $\mathrm{Na}$; e) $\mathrm{Ca} ; \mathrm{f}) \mathrm{Mg}$; g) Al. All elemental values are for total element concentrations. 


\section{Tuff Water Chemistry}

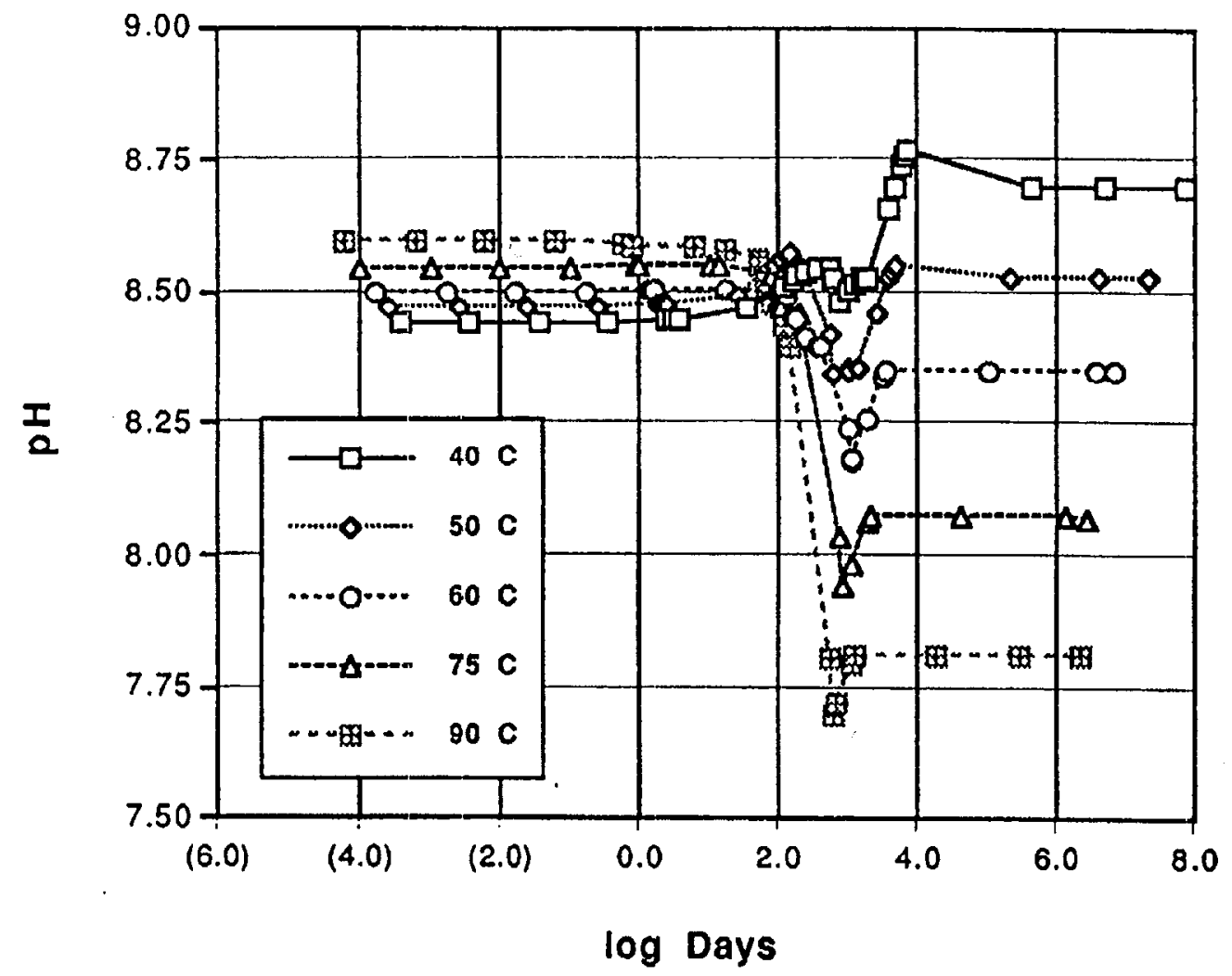

Figure 2a 


\section{Tuff Water Chemistry}

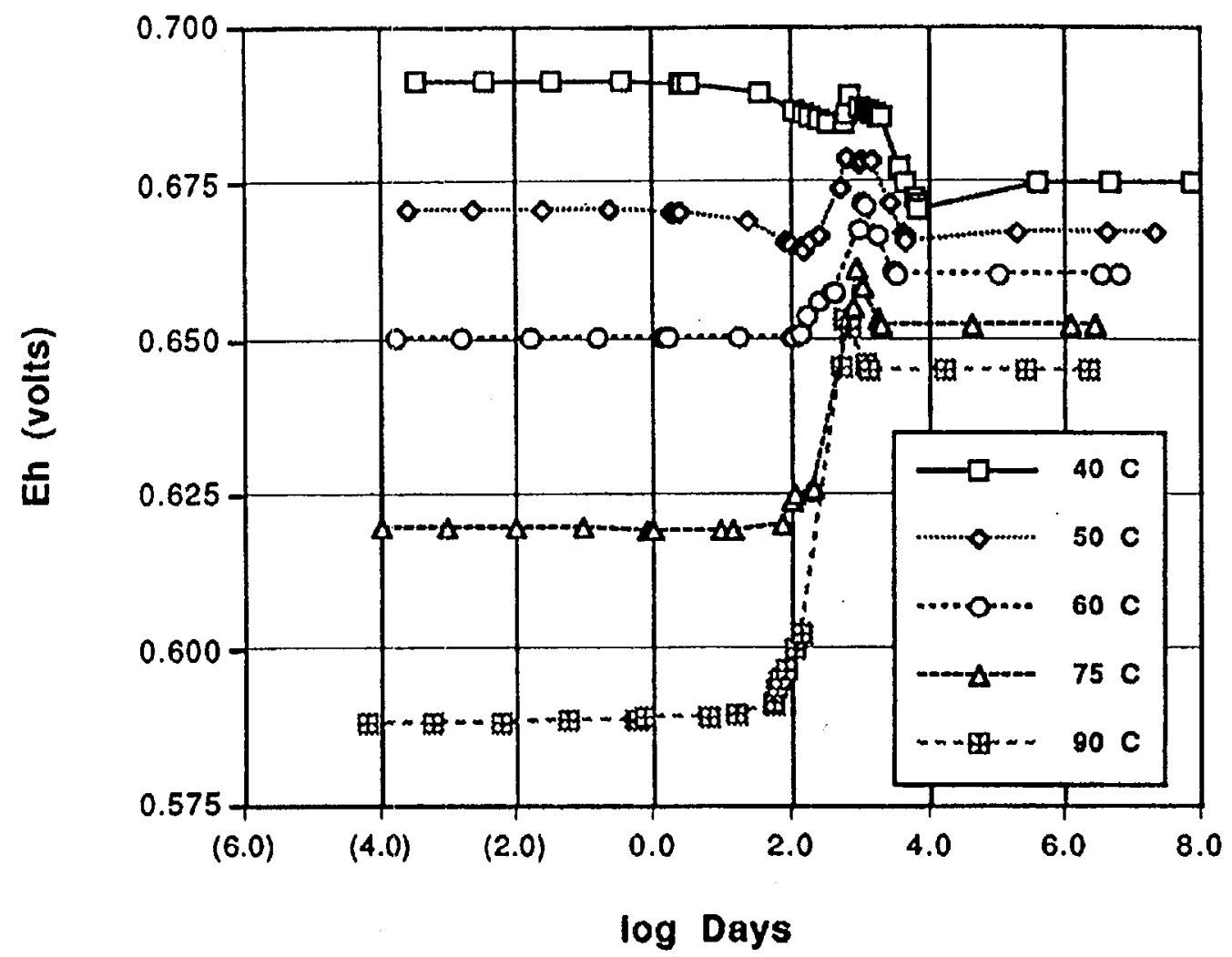

Figure 2b 


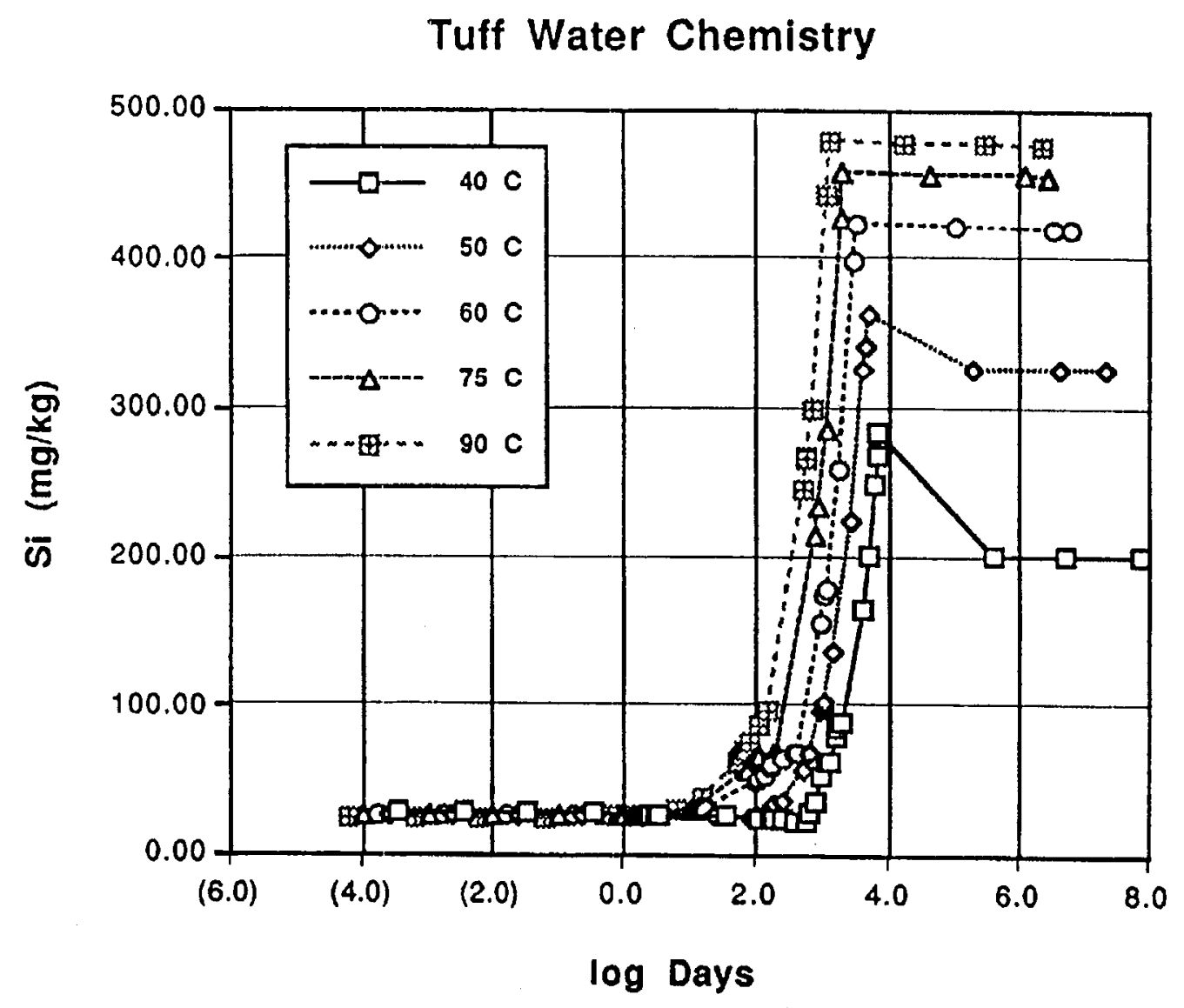

Figure 2c 


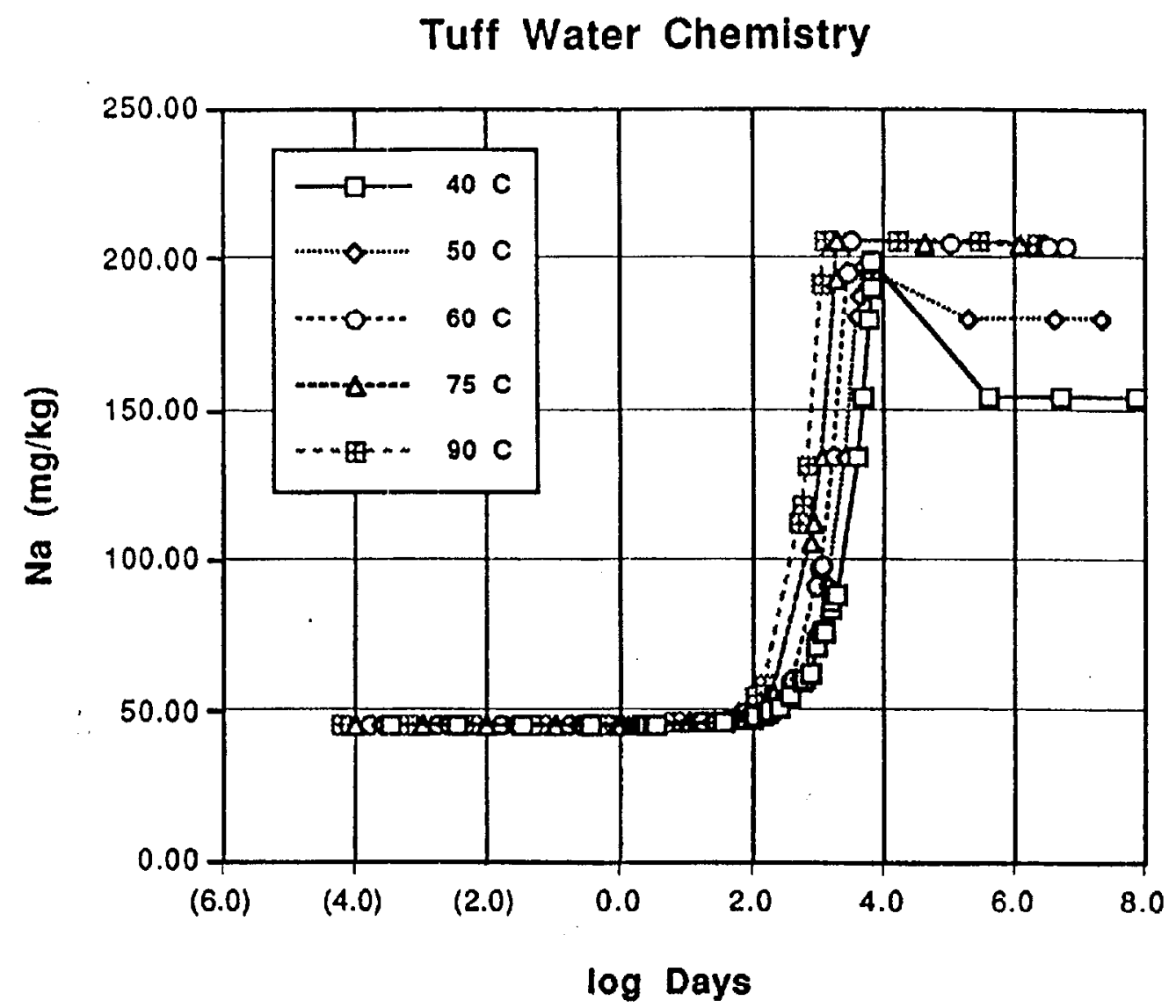

Figure 2d 
Tuff Water Chemistry

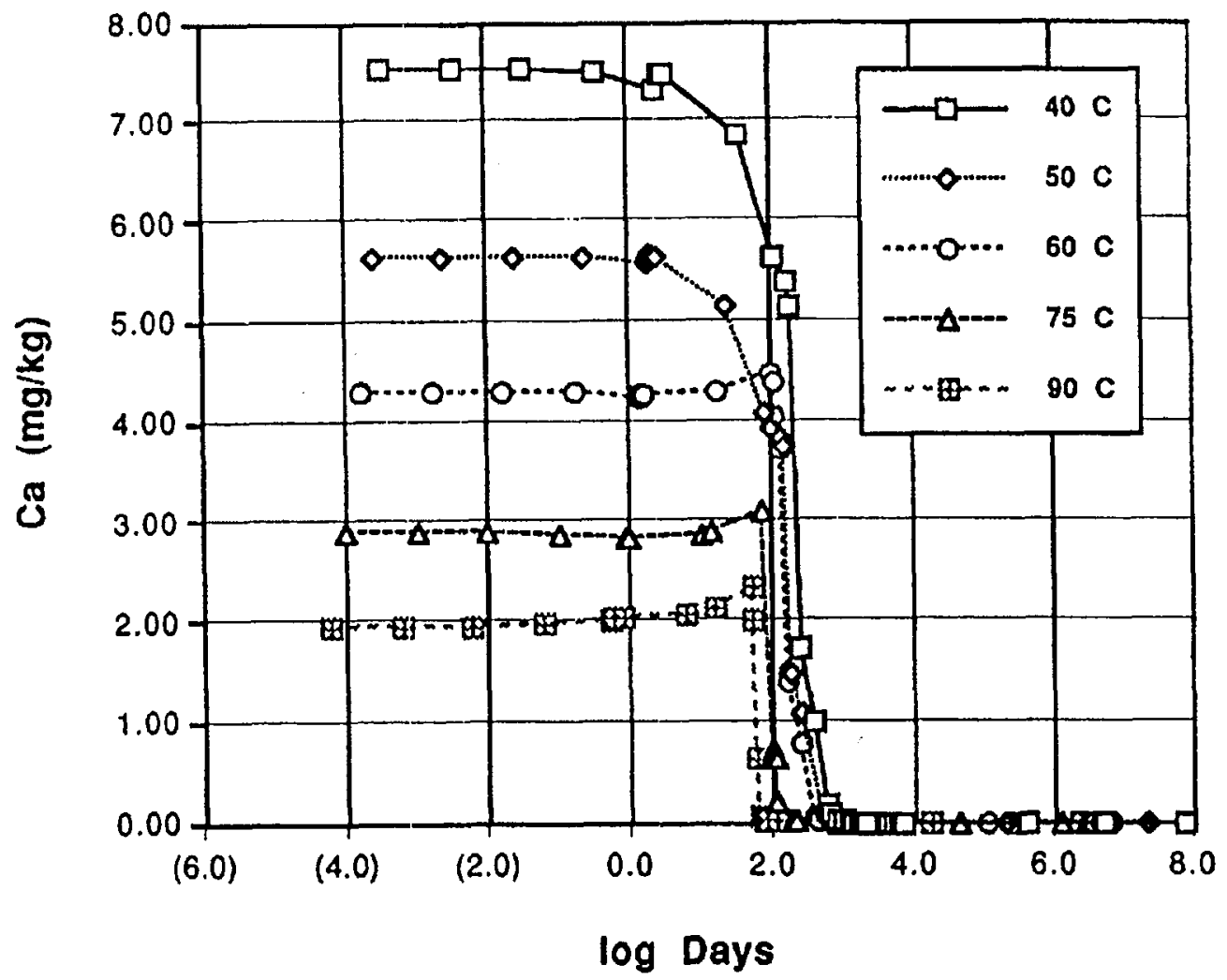

Figure 2e 
Tuff Water Chemistry

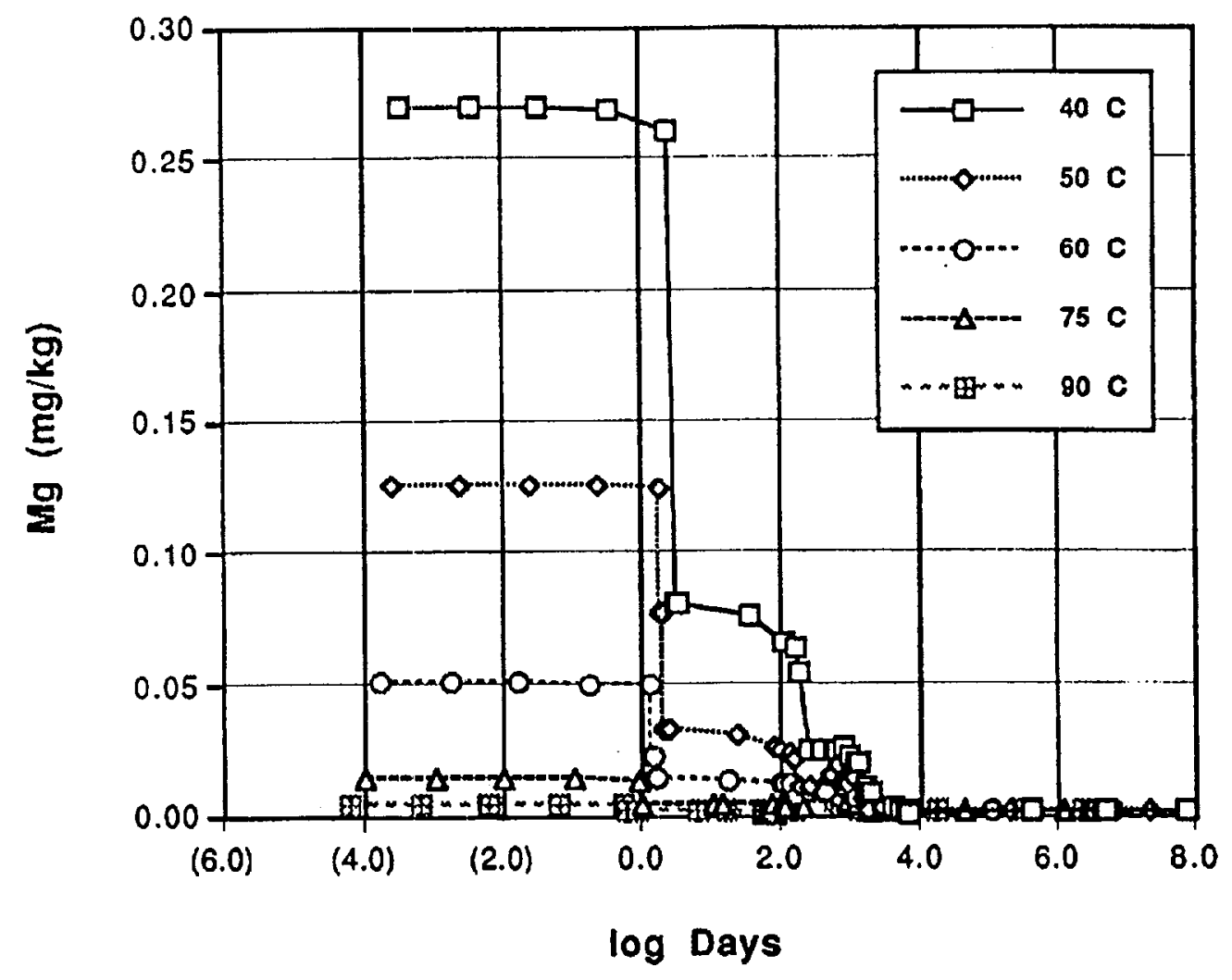

Figure 2f 


\section{Tuff Water Chemistry}

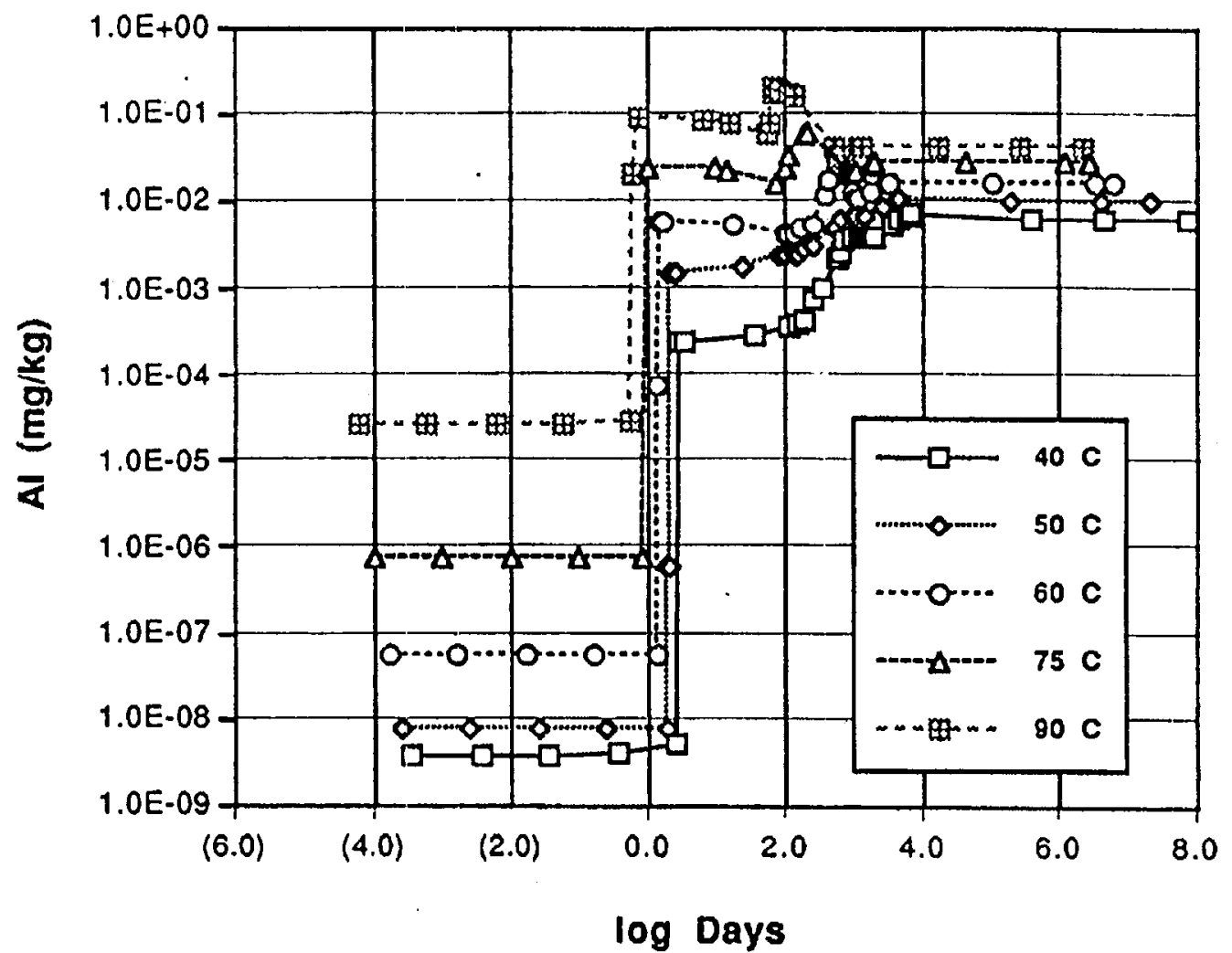

Figure 2g 


\section{Secondary Mineralogy of the Virric Material (Figs. 1 a-e)}

For dissolution of relatively small volumes of glass, the secondary phases that form during reaction progress are similar to those formed in the tuffs (pyrolusite, clays, and zeolites). The principal differences that occur are in the respective amounts of secondary phases, and the specific zeolites that form. At the end of the reaction progress, very similar end points are achieved. The main exception to this is calcite, which persists to the end point of the calculations for all temperatures except $40^{\circ} \mathrm{C}$.

For dissolution of large volumes of glass, the reaction progress is similar to that for small volumes of glass dissolution, for small values of reaction progress, but rather quickly achieves a state in which the only secondary phases that are present are pyrolusite, chalcedony and hematite.

Finally, in none of the simulations with vitric material was muscovite or microcline present as reaction products at any temperature, in contrast to the tuff runs where these two phases are present throughout.

\section{Water Chemistry of the Vitric Material (Figs, 3,a-g)}

Water composition in simulations involving small degrees of glass dissolution reach end points that are nearly identical to those for the tuff-water system, and tend to follow very similar trends during reaction progress. The simulations involving large volumes of glass dissolution followed the same trends early in the simulations, but ultimately achieved much higher total concentrations of all elements except $\mathrm{Si}$, which drops to very low values controlled by large volumes of precipitated chalcedony. The latter buffers aqueous $\mathrm{SiO}_{2}$. Total dissolved silica in these simulations contrasts with that in other runs because the latter also have high concentrations of other Si-bearing aqueous species (e.g., $\left.\mathrm{H}_{6}\left(\mathrm{H}_{2} \mathrm{SiO}_{4}\right)_{4}{ }^{7}\right)$ which are not present in significant quantities in the simulations in which large volumes of vitric material are dissolved. In addition, at high degrees of glass dissolution, $\mathrm{pH}$ drops, reaching acidic values (ca. 3.8) in the low temperature simulations and slightly alkaline (ca. 7.8) at the $90^{\circ} \mathrm{C}$ simulation. This $\mathrm{pH}$ behavior primarily reflects the effects of temperature, and the glass chemistry components, and the solubility of C-bearing species (e.g., $\mathrm{HCO}_{3}{ }^{-}$).

The redox state is effectively determined by the assumption that the solution is in equilibrium with atmospheric gases, except at high degrees of glass dissolution. Under these conditions, strongly oxidizing conditions are generated.

The conservative elements $\mathrm{Cl}, \mathrm{F}, \mathrm{Li}$ and $\mathrm{P}$ were not included in the simulations of the glasses because no analyses were available for them. 

Figure 3: Vitrophyre-water system aqueous compositions for water:rock mass ratio of 57.8, as a function of time and temperature. a) $\mathrm{pH}$; b) Eh; c) Si; d) $\mathrm{Na}$; e) $\mathrm{Ca}$; f) $\mathrm{Mg}$; g) $\mathrm{Al}$. All elemental values are for total element concentrations. For the case in which the water:rock mass ratio was 5763 , the water compositions reached the values shown in these figures at ca. $10^{2}$ days, although in those simulations reaction rates were such that these values were not acheived until ca. $4 \times 10^{5}$ days. 


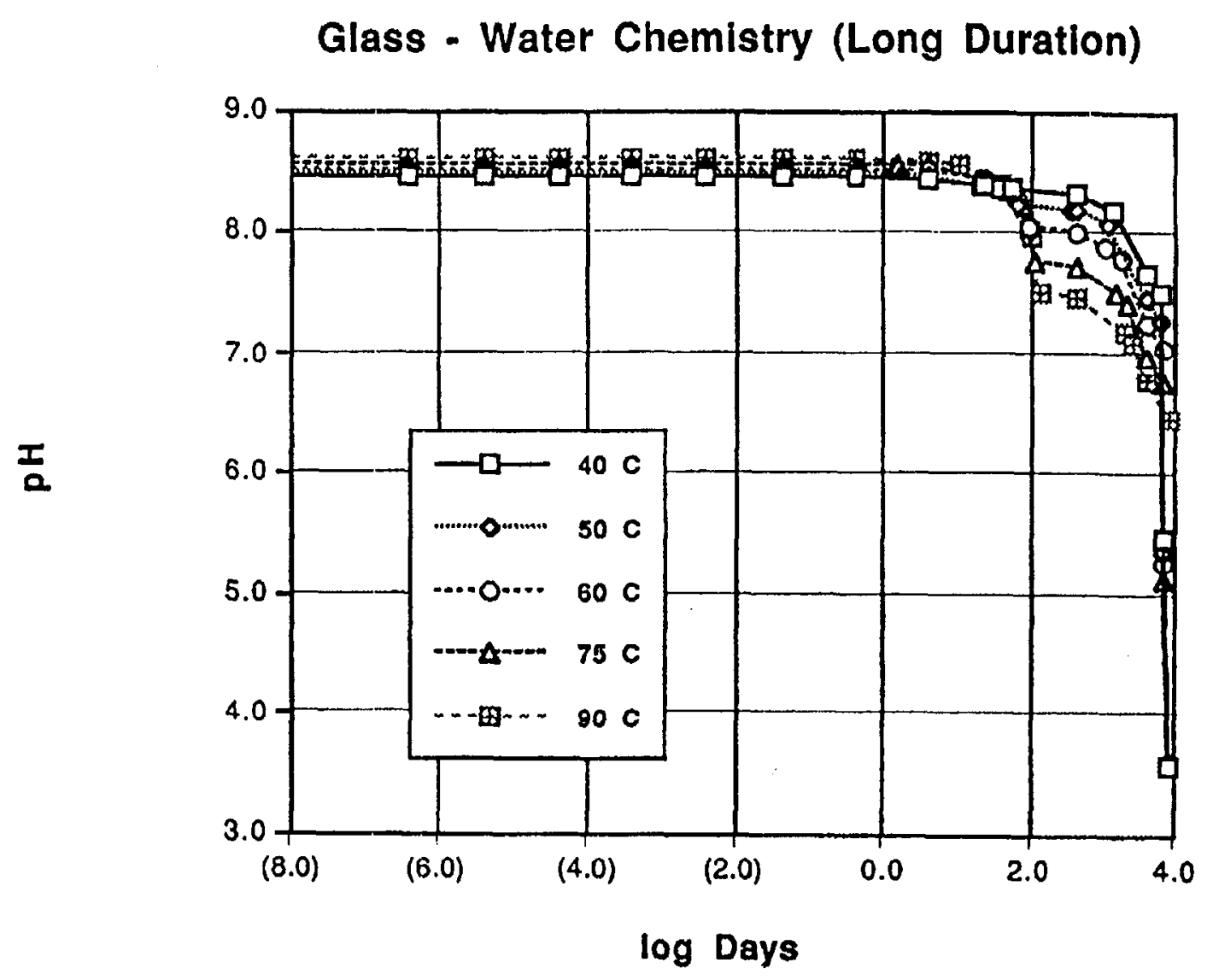

Figure 3a 


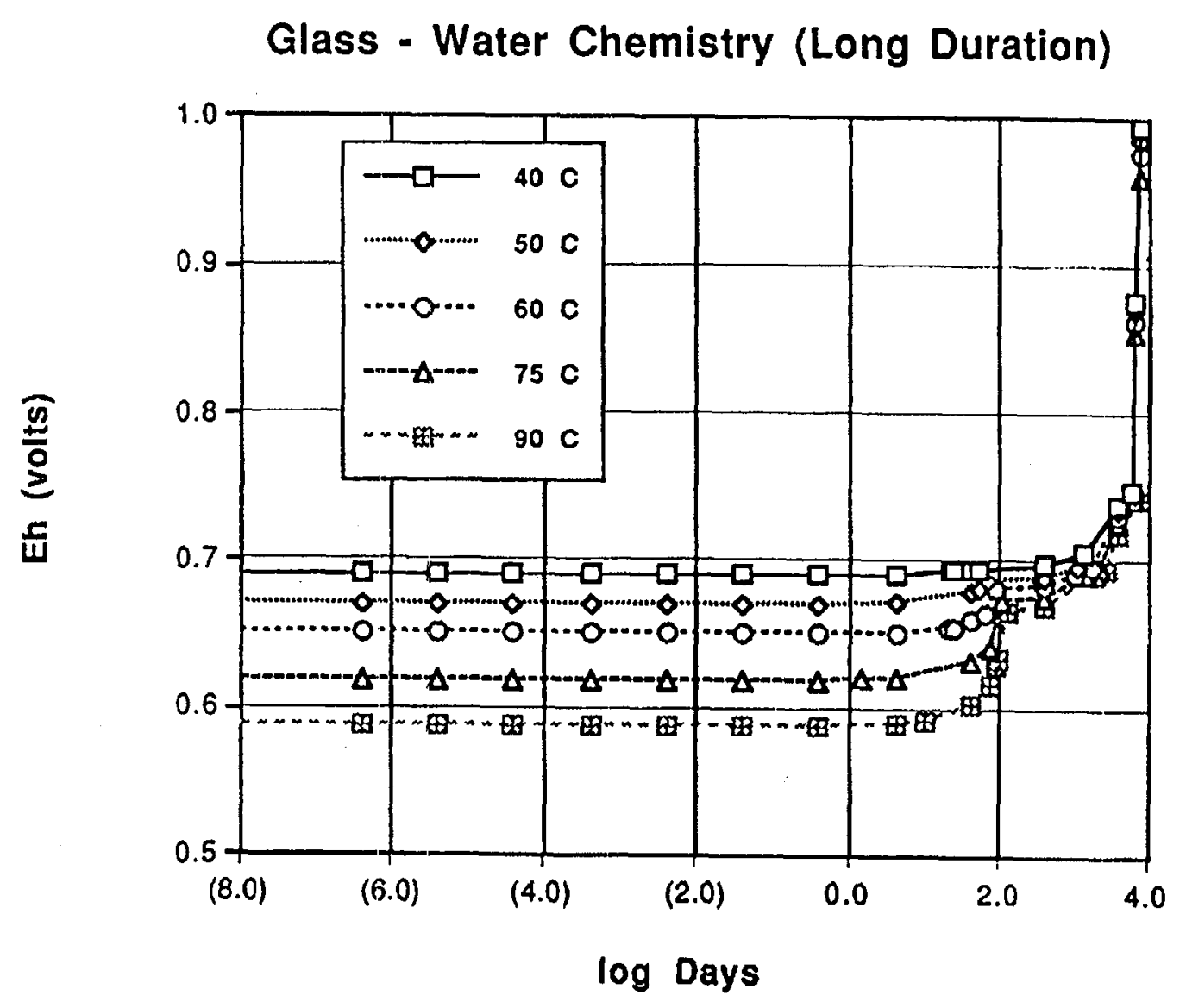

Figure $3 b$ 


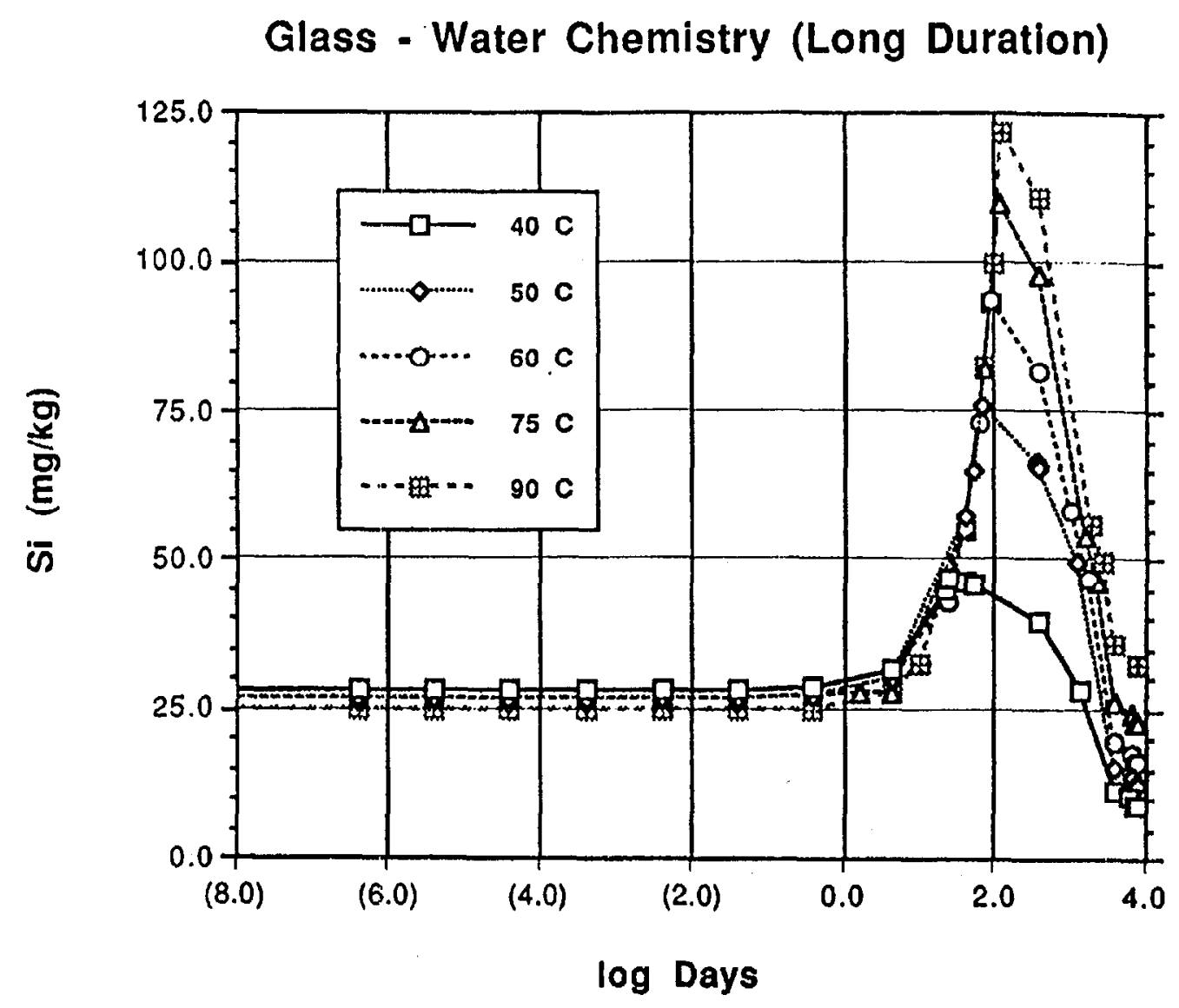

Figure $3 c$ 


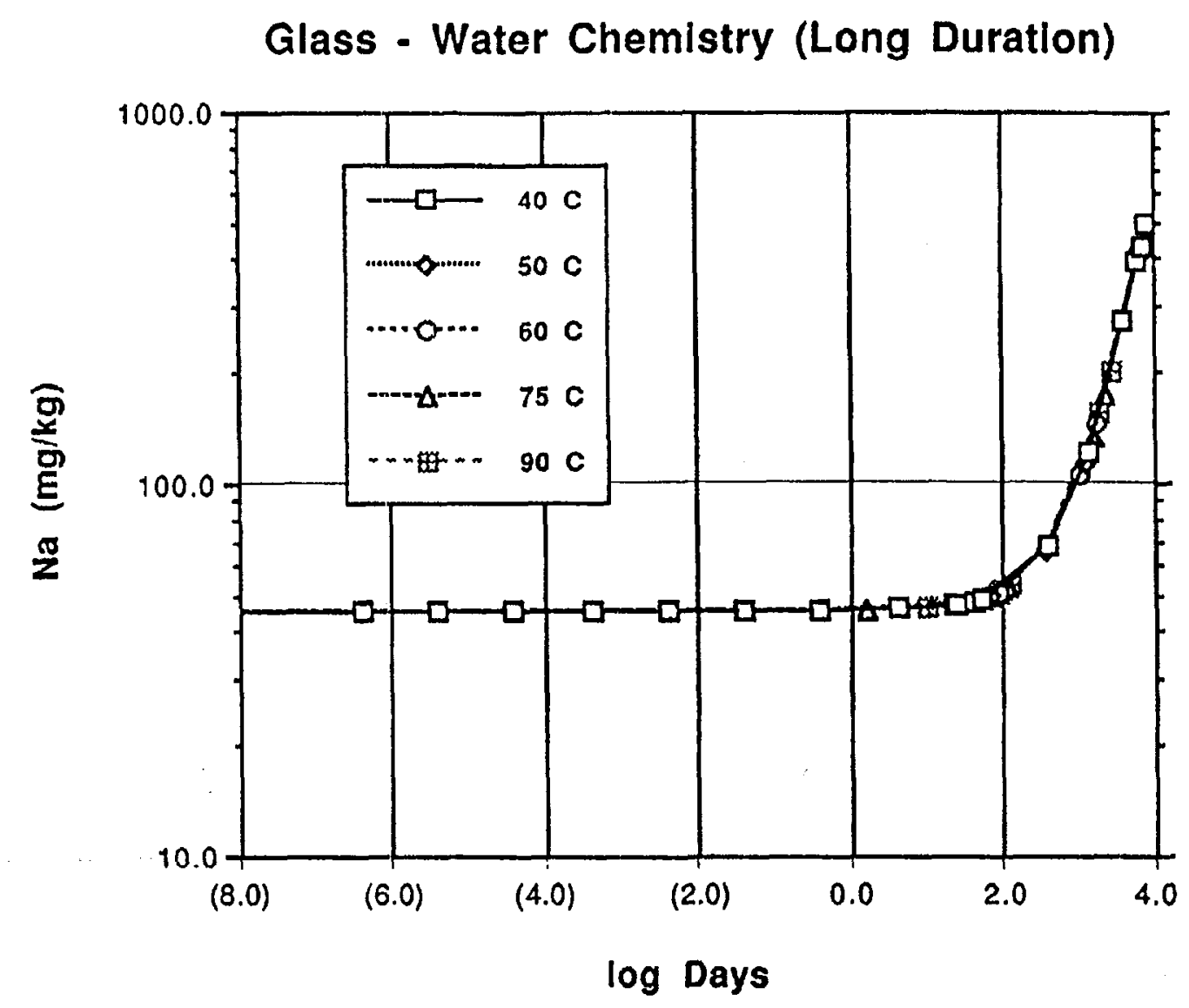

Figure 3d 


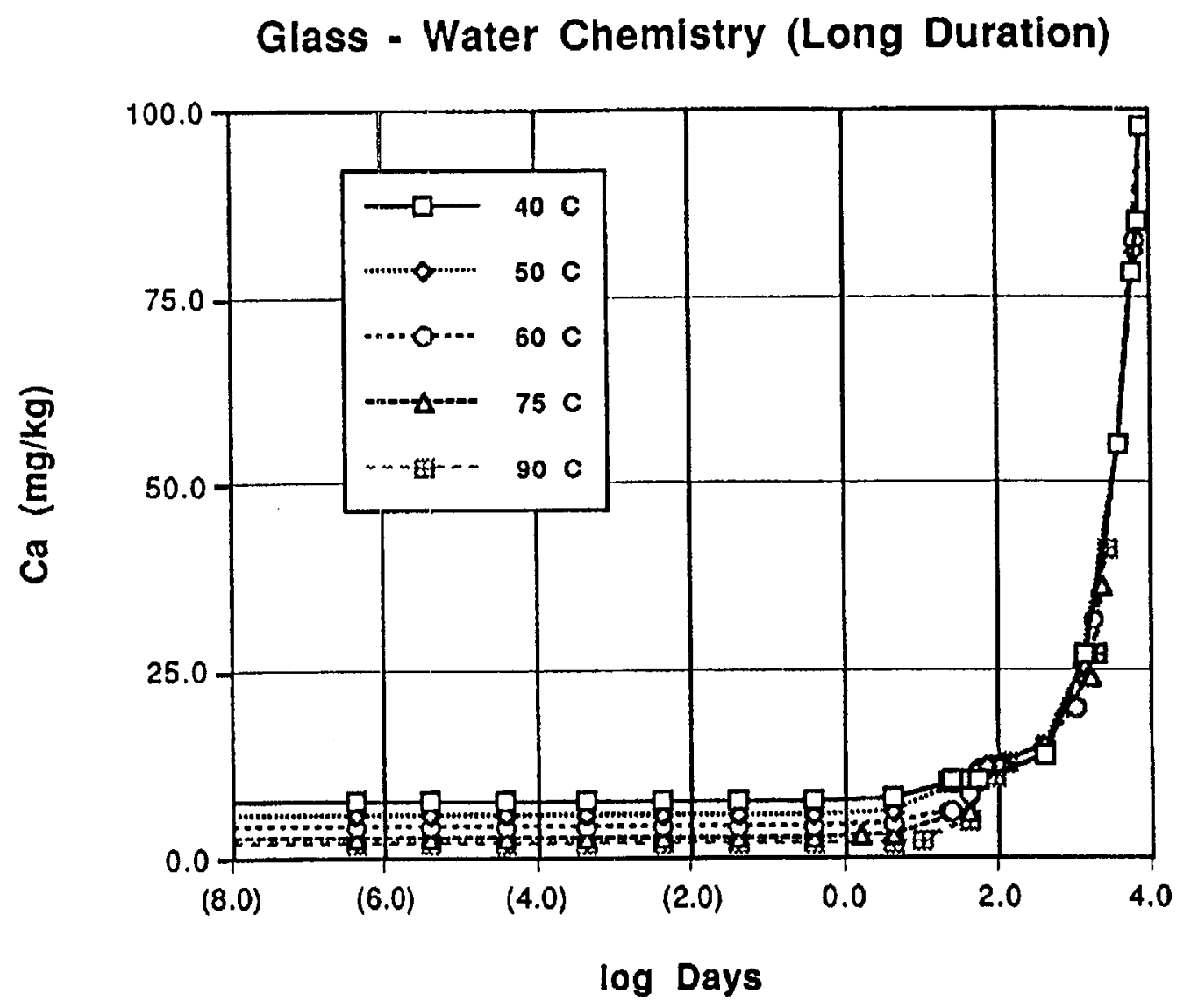

Figure 3e 


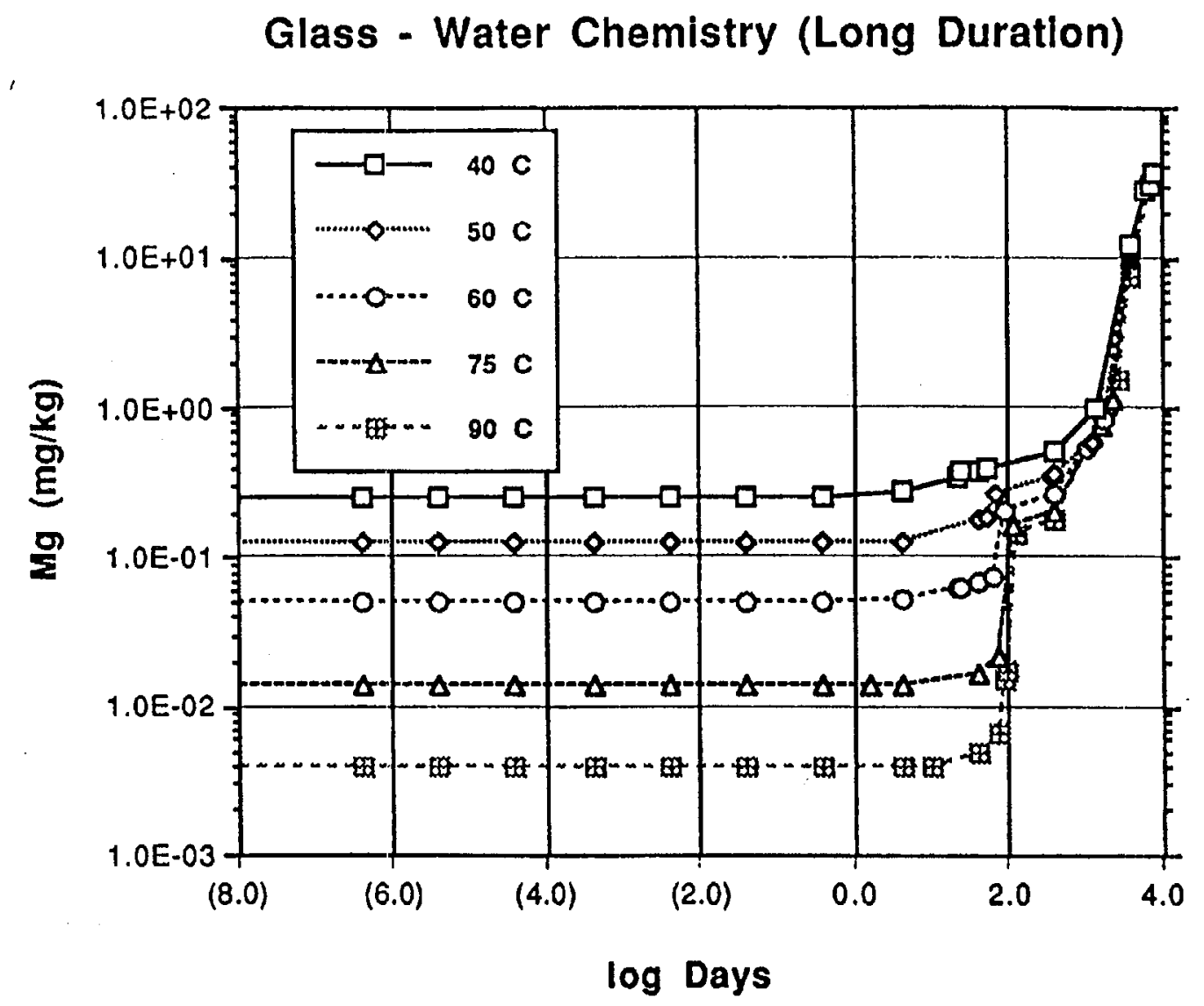

Figure $3 f$ 


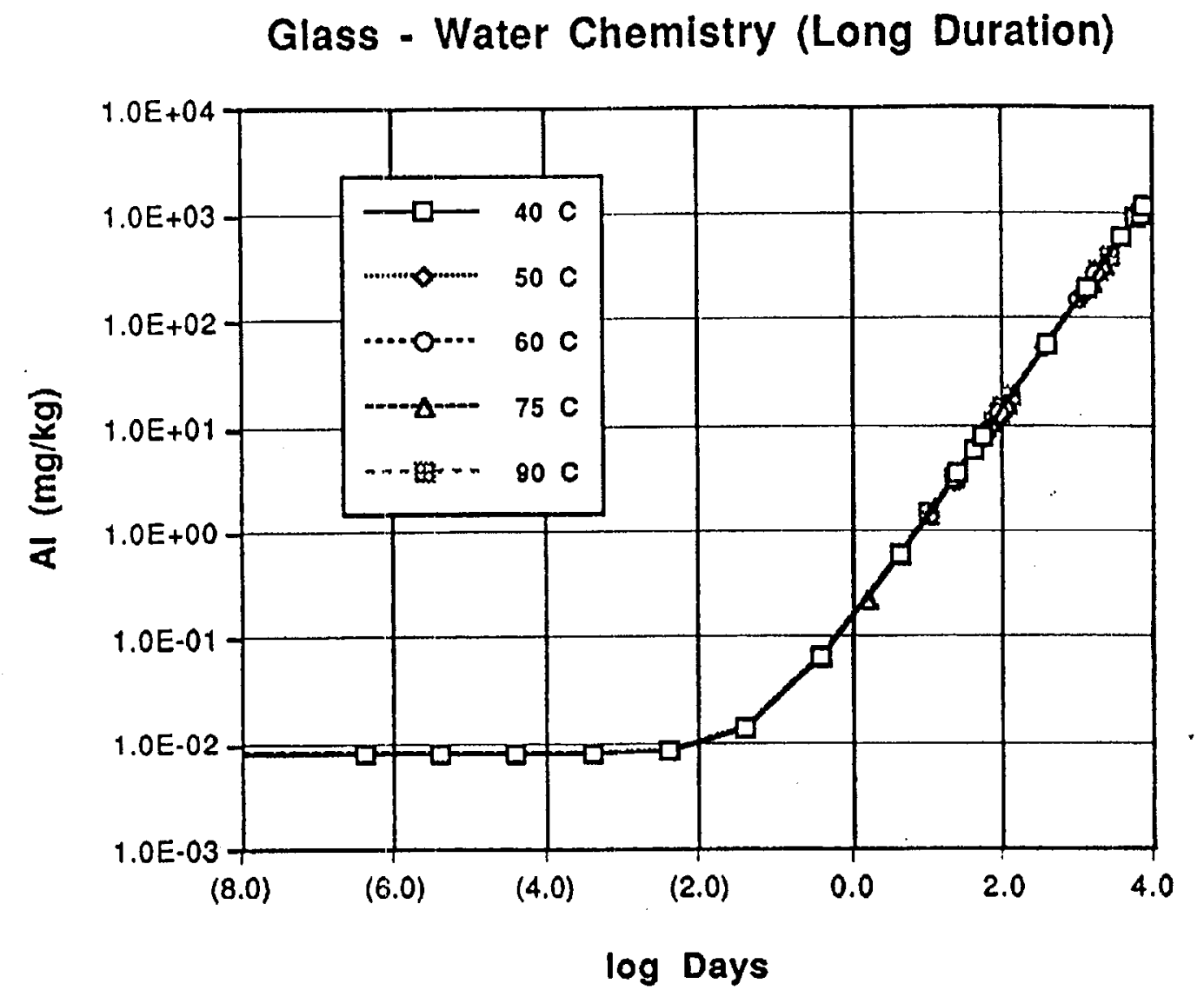

Figure 3g 


\section{Bropagation of Time Emors}

In the first general case examined, the starting conditions were:

$$
\begin{array}{ll}
\mathrm{A} \rightarrow \mathrm{B} \mathrm{k} \mathrm{k}_{0}=100.0 ; & \delta \mathrm{k}_{0} / \mathrm{k}_{0}=[.1-1] \\
\mathrm{B} \rightarrow \mathrm{A} \mathrm{k} 1=10.0 ; & \delta \mathrm{k}_{1} / \mathrm{k}_{1}=0 \\
\mathrm{~B} \rightarrow \mathrm{C} \mathrm{k} 2=20.0 ; & \delta \mathrm{k}_{2} / \mathrm{k}_{2}=[.1-1] \\
\mathrm{C} \rightarrow \mathrm{B} \mathrm{k} \mathrm{k}_{3}=1.0 ; & \delta \mathrm{k}_{3} / \mathrm{k}_{3}=0
\end{array}
$$

The resulting surface (Fig. 4) was computed for $\mathrm{C}$ near its equilibrium value.
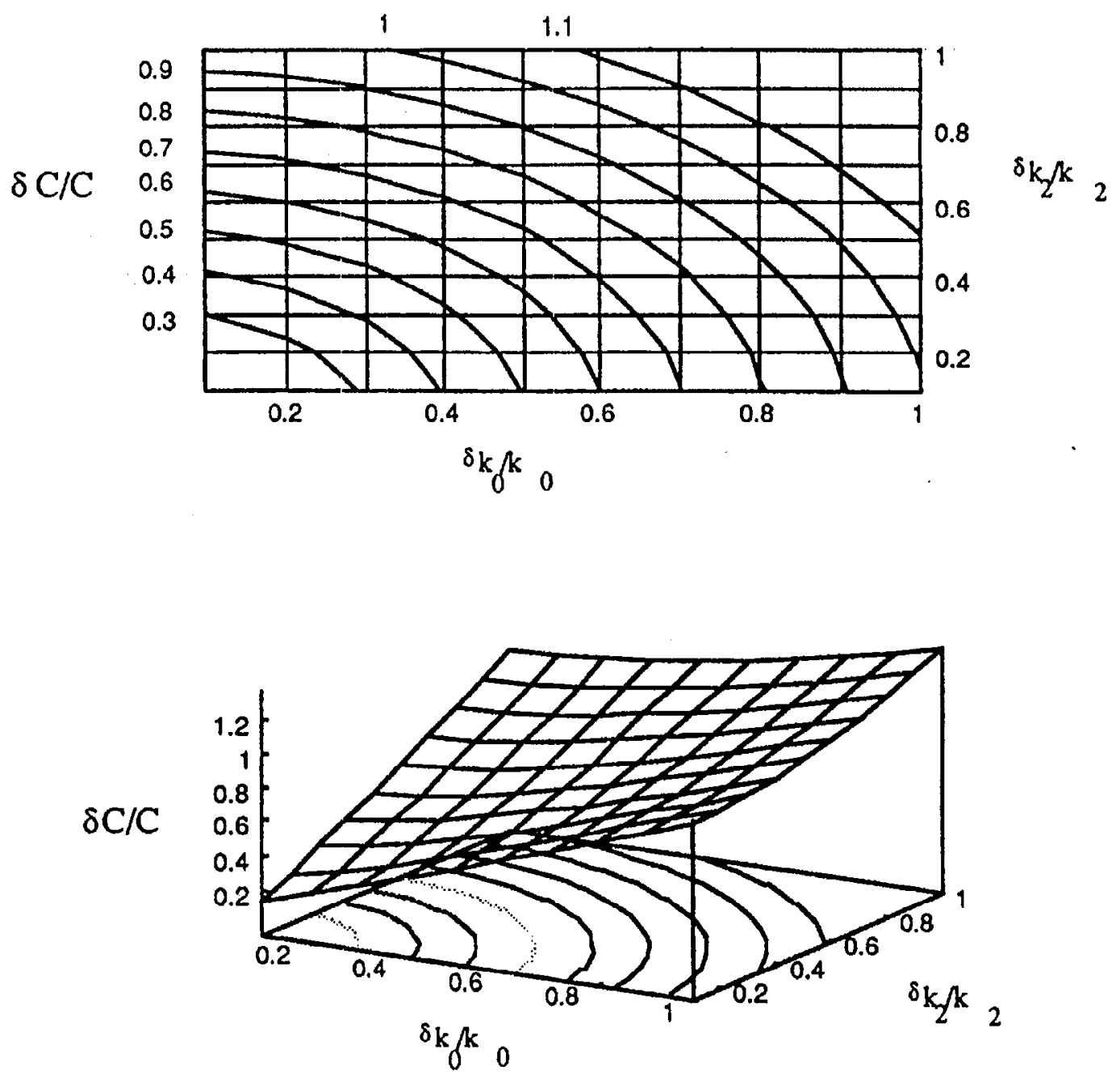

Figure 4. Relative error in $\mathrm{C}$ arising from errors in the forward rate constants; contours are from 0.3 to 1.1 (left to right) in steps of 0.1 . 
The surface is smooth, slightly curved and slopes upward with increased error in the two forward rate constants, as expected. However, increasing the uncertainty in the two forward rate constants (Fig 5) produces a proportionate relative error in the product amount less than the combined relative errors in the rate parameters.

Changing the rate constants by decreasing them to values closer in magnitude to mineral dissolution kinetics illustrates the effect of the scaling function on the propagated error.
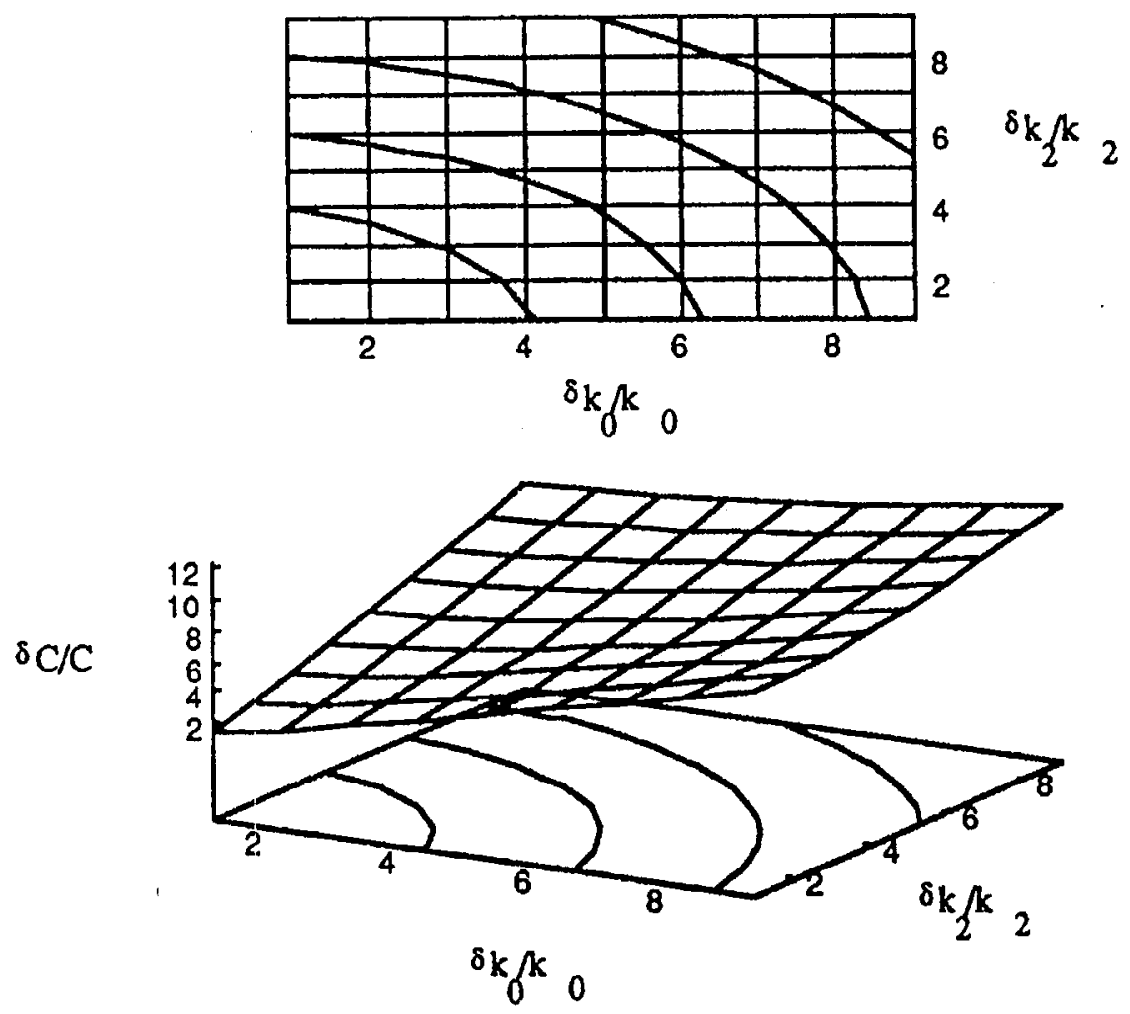

Figure 5. Contour and surface maps for same system with higher uncertainties in $k_{0}$ and k2. Contours are at 4,6,8 and 10 (left to right). 
Using, as another set of starting parameters,

$$
\begin{array}{ll}
\mathrm{k}_{0}=0.001 ; & \delta \mathrm{k}_{0} / \mathrm{k}_{0}=[.1-1] \\
\mathrm{k}_{1}=0.0001 ; & \delta \mathrm{k}_{1} / \mathrm{k}_{1}=0 \\
\mathrm{k}_{2}=0.0005 ; & \delta \mathrm{k}_{2} / \mathrm{k}_{2}=[.1-1] \\
\mathrm{k}_{3}=0.0004 ; & \delta \mathrm{k}_{3} / \mathrm{k}_{3}=0
\end{array}
$$

gives a much greater error (Figure 6), when compared to the first example.

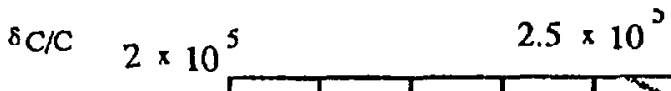

$1.5 \times 10^{5}$

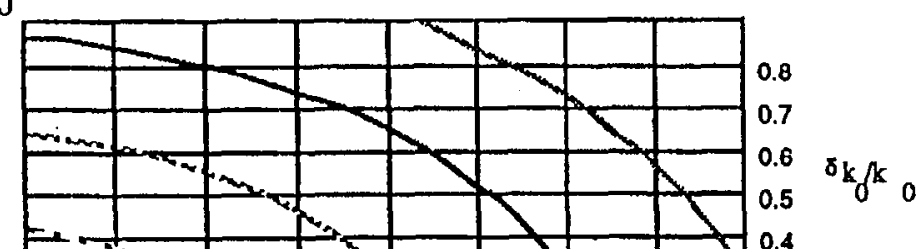

$1 \times 10^{5}$
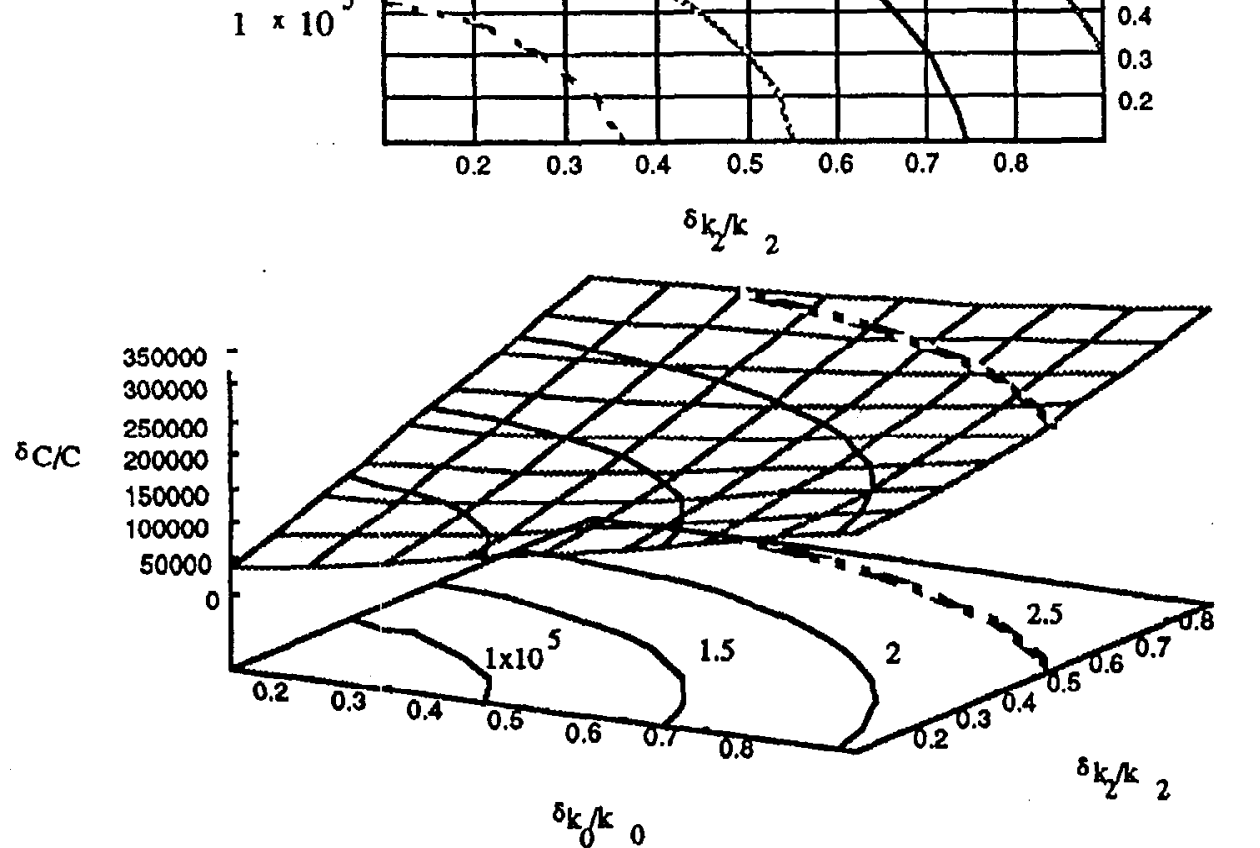

Figure 6. Relative error propagation in slow equilibria model; note the scale on the vertical axis in comparison to figure 1 .

In this example the relative error propagated into the final composition is much greater than the combined relative errors in the rate parameters (by orders of magnitude).

To examine the effects of differences in rates on specific simulations, variation in the sanidine dissolution rate was examined. Since the long simulated time scale of the 
computation impacts the alignment of output results to a common time frame, application of a simple cubic interpolating spline to grid all the runs to a common time axis was attempted.However, this method fails for minerals that go to zero (Figure 7). This is purely a numerical difficulty in computing a partial derivative using finite difference approximation but further illustrates the issue of computability in modeling. A rational interpolation performs better and is used for subsequent calculations to grid the runs to a common time axis. For the case where small differences in the rate are considered (Figure 7), the model results are counter-intuitive. It is suspected that the simulation results reflect computational artifacts propagated through round-off errors.

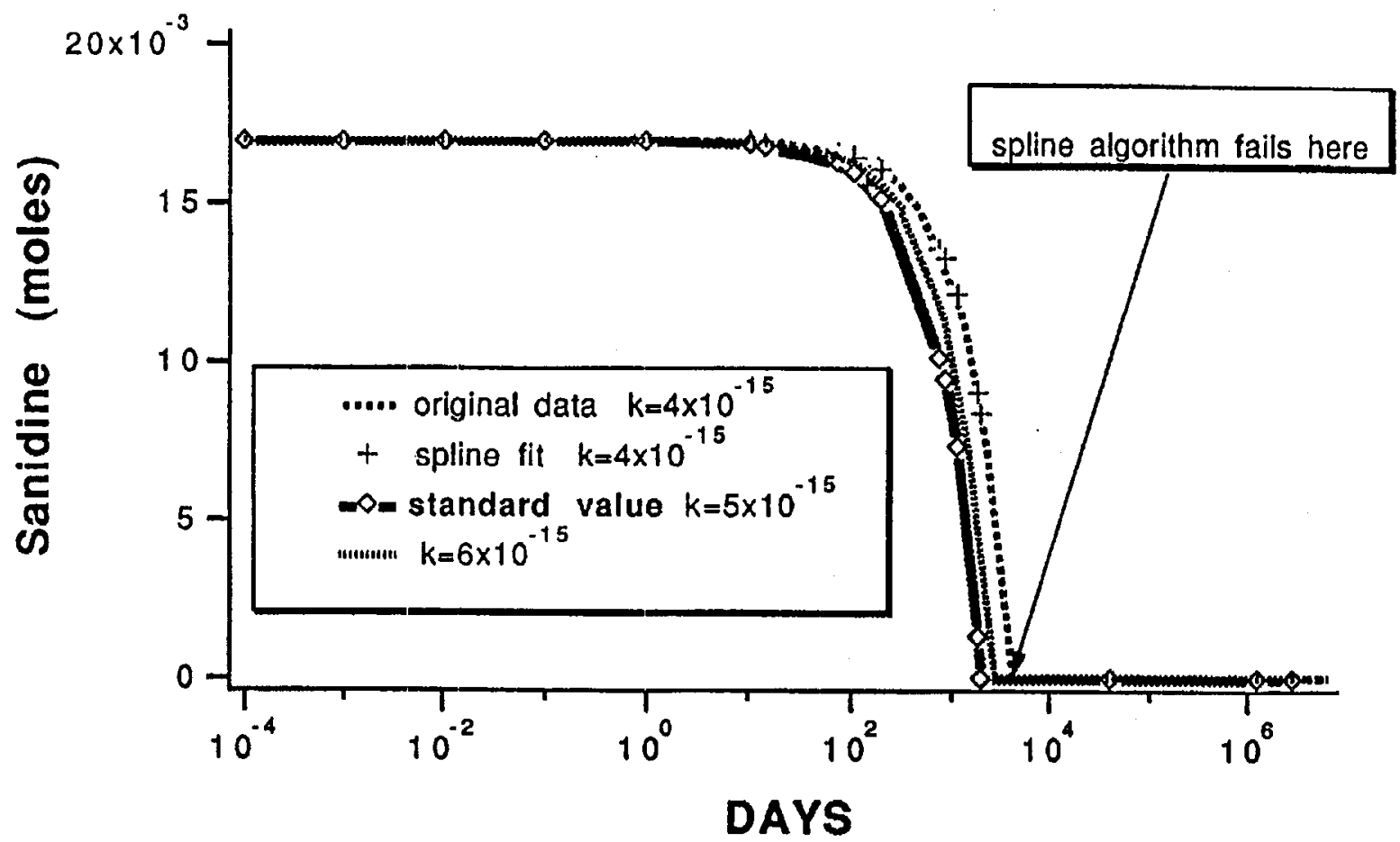

Figure 7. Changes in sanidine resulting from $20 \%$ changes in its reaction rate; crosses show effect of spline used to grid data to a common time axis.

Increasing or decreasing the sanidine dissolution rate constant by a much greater amount results in the expected effects (Figure 8), although these larger values make less accurate the numerical approximation to the partial derivative.

To determine the propagated uncertainty in the amount of sanidine formed at a given time, we used the results shown in Figure 8. In using these results, it is assumed that the chemical changes are smooth, continuous, single valued functions, and that the slope (i.e. the partial derivative) is the same with a $20 \%$ change in the rate constant as it is using the order of magnitude change. Approximate error bars, generated by differencing the runs 
shown in Figure 8, are useful for visualizing the magnitude of the possible uncertainty in amount of sanidine. The results (Fig. 9) demonstrate that the propagated error increases with time. In addition, the 'error' or uncertainty in the result has two aspects- the amount and when the amount is oberved (e.g. when sanidine vanishes) - the error in predicting when a phase appears or disappears from the model can be substantially greater than the prediction of the amount made. For example, the maximum uncertainty in the amount of sanidine produced is ca $50 \%$, but the uncertainty of when it is consumed is ca $-60 \%$ to + $2100 \%$.

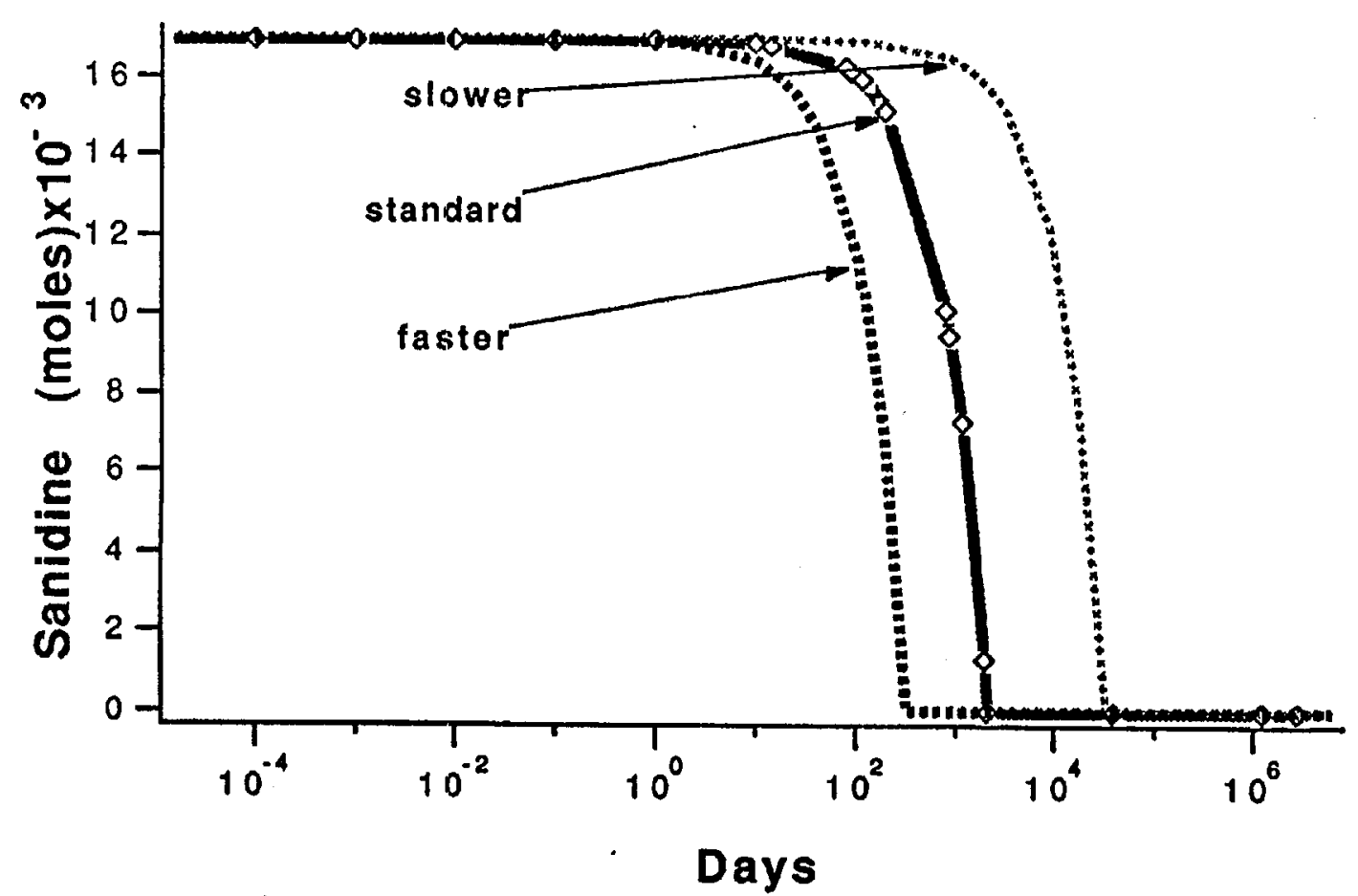

Figure 8. Changes in sanidine resulting from order of magnitude changes in its reaction rate. 


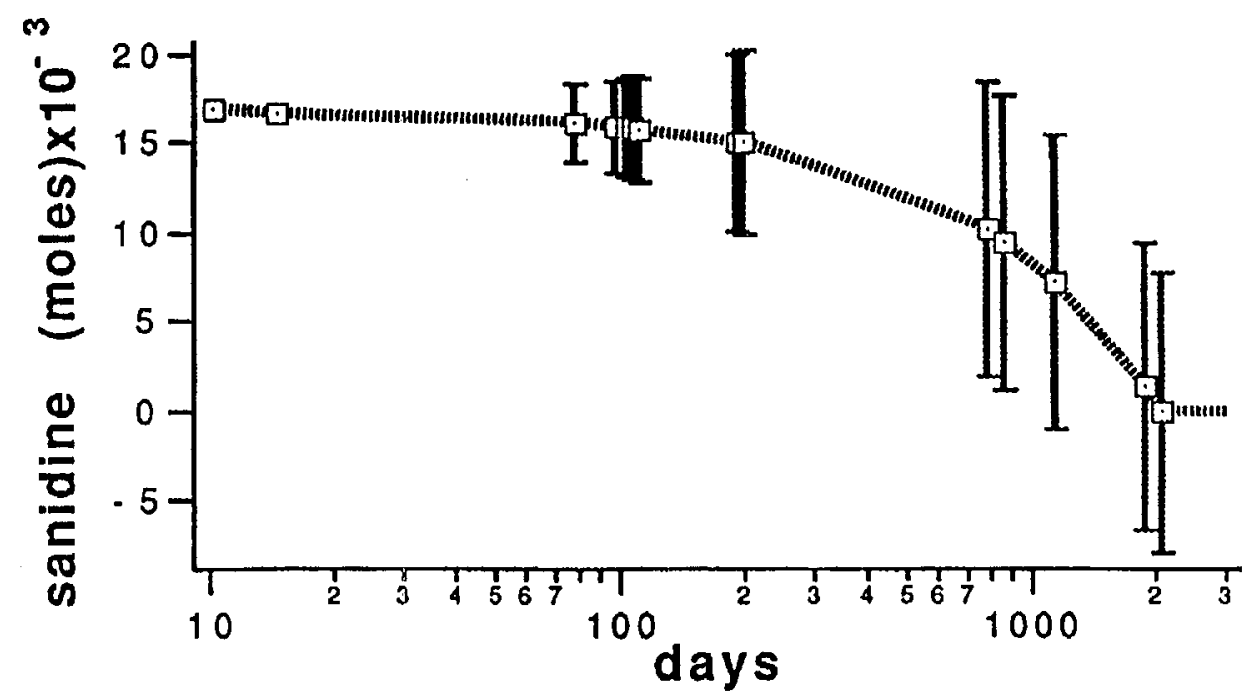

Figure 9. Changes in sanidine resulting from large (10x) changes in its reaction ratc, the difference shown as the average error bars.

\section{DISCUSSION}

The simulations that were conducted were designed to be the preliminary simulations for bounding water compositions that could evolve within the Altered Zone and migrate into the Near-Field Environment, and for bounding the mineralogy that could evolve in the Altered Zone. Emphasis, therefore, is placed on establishing a baseline upon which refinements would be made at a future date. Before describing the important baseline information, the key constraints upon which the simulations are based need to be reiterated.

\section{Model Constraints}

The constraint of constant gas fugacity has a strong influence on the geochemical evolution during reaction progress (e.g., Glassley, 1995). This extends most importantly to $\mathrm{pH}$ change, carbonate formation, and the concentrations of a variety of ions in solution.

The suppression of certain phases from precipitating can have an important influence on chemical and mineralogical evolution. The selection of which phases to suppress is a matter of experienced judgment, and needs to be done with particular conditions in mind. This suite of simulations, which was designed to provide a preliminary baseline, suppresses only three phases that are known to be difficult to nucleate or which are superseded by other phases that may be less thermodynamically stable. Future work needs to consider which specific phases are reasonable suppress, under different sets of conditions. This is particularly important with respect to clays and zeolites. A wide range of 
different zeolites and clays occur at various stages in the simulations, reflecting the small differences in thermodynamic properties of these phases, and their relative sensitivities to chemical conditions. Whether or not these particular zeolites or clays will occur, and in what sequence during reaction progress, needs much further investigation. Particularly important in this regard are the thermodynamic properties of the phases, and their ion exchange characteristics, and how these will change as different mineral phases are suppressed.

The time indicated for reaction progress in the figures is dependent upon the selection of rate constants and surface areas. These parameters, particularly the effective surface area in a system, can be highly uncertain. As a result, time at which particular phases appear, or at which certain chemical conditions are established, should be viewed more as illustrative of sequences of conditions, rather than absolute times, until more information is available. The simulations in which tuff alteration was considered have water volume to surface area ratios typical of experiments conducted in Dickson rocking autoclaves, and thus represent those scenarios in which very large volumes of water are present, relative to the accessible effective surface area. The simulations involving the vitric material, on the other hand, cover a very wide range of possible accessible surface areas, and thus represent a range of conditions from water flow in fractures, to water wetting non-welded, highly porous vitric materials.

\section{Key Information Regarding Baseline Secondary Mineralogy}

Under all conditions, clays and zeolites occur within the secondary mineral assemblages. The specific time in the reaction progress when these phases may appear, and the compositions and structures that will occur may vary, depending on the evolving chemical conditions and temperatures. The respective volumes that develop, at steady state conditions, are generally less than other coexisting alumino-silicates. These phases, nevertheless, form an important part of the secondary assemblages, due to their potentially important role as materials in which radionuclides may be sequestered.

Silica polymorphs develop early on in reaction progress. This is an important observation, since silica polymorphs are the most abundant secondary phases to form, in all conditions. This suggests that silica may play an important role in coupling hydrology and geochemistry/mineralogy via precipitation/dissolution-induced changes in porosity and permeability, and transport.

In all of the simulations, carbonates play an important role in the secondary mineral assemblage, but they are not always present when steady state is reached. Because 
carbonates may be important in both influencing water composition and sequestering ${ }^{14} \mathrm{C}$ through isotope exchange, the ubiquitous presence of this phase in various stages during reaction progress may be significant.

\section{Key Information Regarding Baseline Water Composition}

The composition of water that may enter the NFE is restricted to a relatively narrow range, except for the condition in which large volumes of glass are dissolved. For those conditions not involving large volumes of glass, the bounds suggest that the solution will be approximately neutral to slightly basic, relatively oxidizing, saturated in a silica polymorph, and with low to moderate concentrations of dissolved species. Total ionic strength remains below 0.1 molal. For the case where large volumes of glass are dissolved, pH may become strongly acidic, and total dissolved species can be quite high.

Despite these characteristics, solution composition changes significantly during the course of reaction progress. For the non-conservative elements, changes in concentration of many times are evident, and correlated with the dissolution or precipitation of a specific phase or phases.

\section{Error Propagation}

The calculations conducted for the general coupled reaction case focus on the error in constituent amounts at final equilibrium rather than the maximum error that may occur in a simulation. The uncertainty in final constituent amounts indicated from these calculations is shown to be problem specific and potentially significant with respect to long term prediction of geochemical properties in slowly reacting systems, such as systems involving mineral dissolution or precipitation. For systems in which rates are very slow, as in dissolution of silicate minerals, the uncertainties in constituent amounts range from the same relative magnitude as the input parameter uncertainties to many orders of magnitude greater. The results in which sanidine was considered demonstrate that there is an increase in the uncertainty of the amount of mineral that may be present, for a relatively small initial uncertainty in the rate parameter. The response of the overall system to a small perturbation in rate parameters is clearly complex and non-linear.

\section{CONCLUSIONS}

The results presented here provide initial bounds on secondary mineralogy and water chemistry, for a very specific set of conditions and simulation constraints. These constraints, summarized in the Discussion section and in the tables and figures, along with 
similar efforts to bound pone water chemistry during evaporation (Glassley, 1995), provide baseline information from which to further refine simulation strategies and thus refine bounds on water chemistry and secondary mineralogy.

These results also document the very great uncertainties that exist in establishing the nature of secondary minerals that may form, the resulting water chemistry, and the absolute times at which specific changes might be expected to develop during reaction progress. Much work is still needed before quantitative bounds can be confidently placed on the evolution of water chemistry entering the NFE, and the resulting secondary mineral assemblages that may influence radionuclide migration.

The preliminary results with respect to propagation of uncertainty in the dissolution rate constants indicate that this is an important issue in the interpretation of model results. These results clearly document that both the times at which mineral phases may be present or absent during reaction progress, and their respective amounts, may be uncertain by orders of magnitude. Because these parameters are also important for the water chemistry, as a function of time, it is clear that only very gross bounds can be placed on either the mineralogical or water chemistry evolution, unless more measurements of dissolution and precipitation rates are obtained.

This point is also important for radionuclide retardation in the EBS or Altered Zone. The magnitude of retardation depends upon the mineral phases that are present, and their respective amounts. However, these results demonstrate that there is substantial uncertainty about when any specific phase may form or be consumed in reactions. This uncertainty will remain until further work is completed to establish more precise values for dissolution and precipitation kinetics rate constants.

It should also be borne in mind that these water chemistries are not the chemistries that a waste package is likely to see. Materials introduced into the repository during construction and waste emplacement will probably be the primary controls on water chemistry in the NFE. 


\section{REFERENCES}

L. Brisqueu \& H de la Boisse, (1990) U-Pb geochronology: Systematic development of mixing equations and application of Monte Carlo numerical simulation to the error propagation in the Concordia diagram, Chemical Geology, 88, 69-83.

Broxton, D.E., W.G. Warren, R.C. Hagen, and G. Luedemann. (1989), Chemistry of Diagenetically Altered Tuffs At A Potential Nuclear Waste repository at Yucca mountain, Nevada. Los Alamos National Laboratory, Los Alamos, New mexico, LANL-10802-MS.

Buscheck, T. A., and J. J. Nitao (1992), The Impact of Thermal Loading on Repository Performance at Yucca Mountain, in Third International Conference on High Level Radioactive Waste Management, Las Vegas, American Nuclear Society, LaGrange Park, Ill., 1003-1017.

Buscheck, T. A., and J. J. Nitao (1993), The Impact of Repository-Heat-Driven Hydrothermal Flow on Hydrological Performance at Yucca Mountain, Lawrence Livermore National Laboratory, Livermore, Calif., UCRL-JC-112444.

Delany, J. M. (1985), Reaction of Topopah Spring Tuff with J-13 Water: A Geochemical Modeling Approach Using the EQ3/6 Reaction Path modeling Code, Lawrence Livermore National Laboratory, Livermore, Calif., UCRL-53631, 48p.

Glassley, W. E. (1995), Report on Near-Field Geochemistry: Water Composition Changes Due to Evaporation. Yucca Mountain Milestone MOL, 206.

Harrar, J.E, J.F. Carley, W.F. Isherwood, and E. Raber. (1990), Report of the Committee to Review the Use of J-13 Well Water in the Nevada Nuclear Waste Storage Investigation, Lawrence Livermore National Laboratory, Livermore, Calif., UCID-21867.

Holdren, G.R. Jr., and P.M. Speyer (1985), "Reaction rate-surface area relationships during the early stages of weathering: $\mathrm{I}$. Data on eight additional feldspars," Geochim. Cosmochim. Acta 51, 2311-2318.

Nitao, J. (1988), Numerical Modeling of the Thermal and Hydrological Environment Around a Nuclear Waste Package Using the Equivalent Continuum Approximation: Horizontal Emplacement, Lawrence Livermore National Laboratory, Livermore, CA, UCID-21444.

Thompson, A.M., and R.W. Stewart, (1991), Effect of Chemical-Kinetics Uncertainties on 
Calculated Constituents in a Tropospheric Photochemical Model, J. Geophysical Research, 96, 13089-13108.

Wolery, T. (1992a), EQ316, A Software Package for Geochemical Modeling of Aqueouis Systems: Package Overview and Installation Guide (Version 7.0), Lawrence Livermore National Laboratory, Livermore, CA, UCRL-MA-110662 PT I.

Wolery, T. (1992b), EQ3NR, A Computer Program for Geochemical Aqueous SpeciationSolubility Calculations: Theoretical Manual, User's Guide and Related Documentation (Version 7.0), Lawrence Livermore National Laboratory, Livermore, CA, UCRL-MA-110662 PT. III.

Wolery, T. and S. A. Daveler (1992), EQ6, A Computer Program for Reaction Path Modeling of Aqueous Geochemical Systems: Theoretical Manual, User's Guide and Related Documentation (Version 7.0), Lawrence Livermore National Laboratory, Livermore, CA, UCRL-MA-110662 PT. IV.

Wolery, T., K. J. Jackson, W. L. Bourcier, C. J. Bruton, B. E. Viani, K. G. Knauss, and J. M. Delany (1990), "Current Status of the EQ3/6 Software Package for Geochemical Modeling," in Chemical Modeling in Aqueous Systems II. 


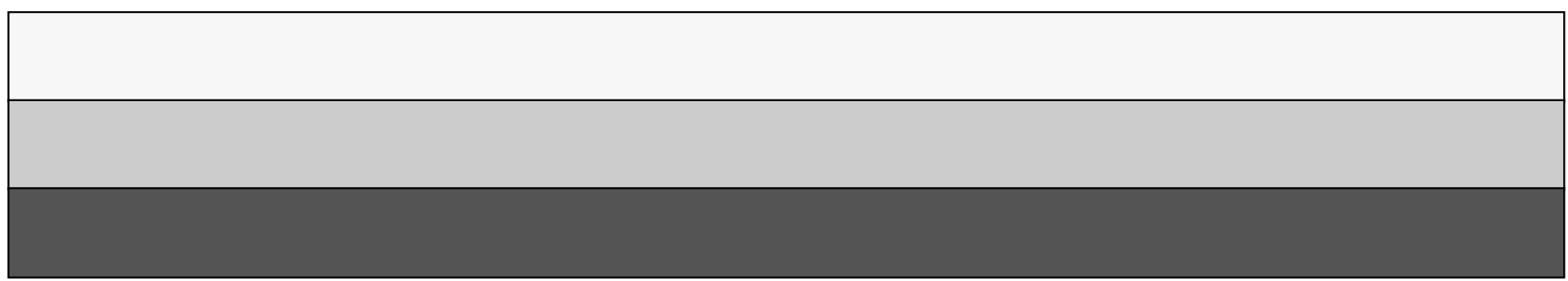

